\title{
A Social Impact Assessment and Management Methodology Using Social Indicators and Planning Strategies
}

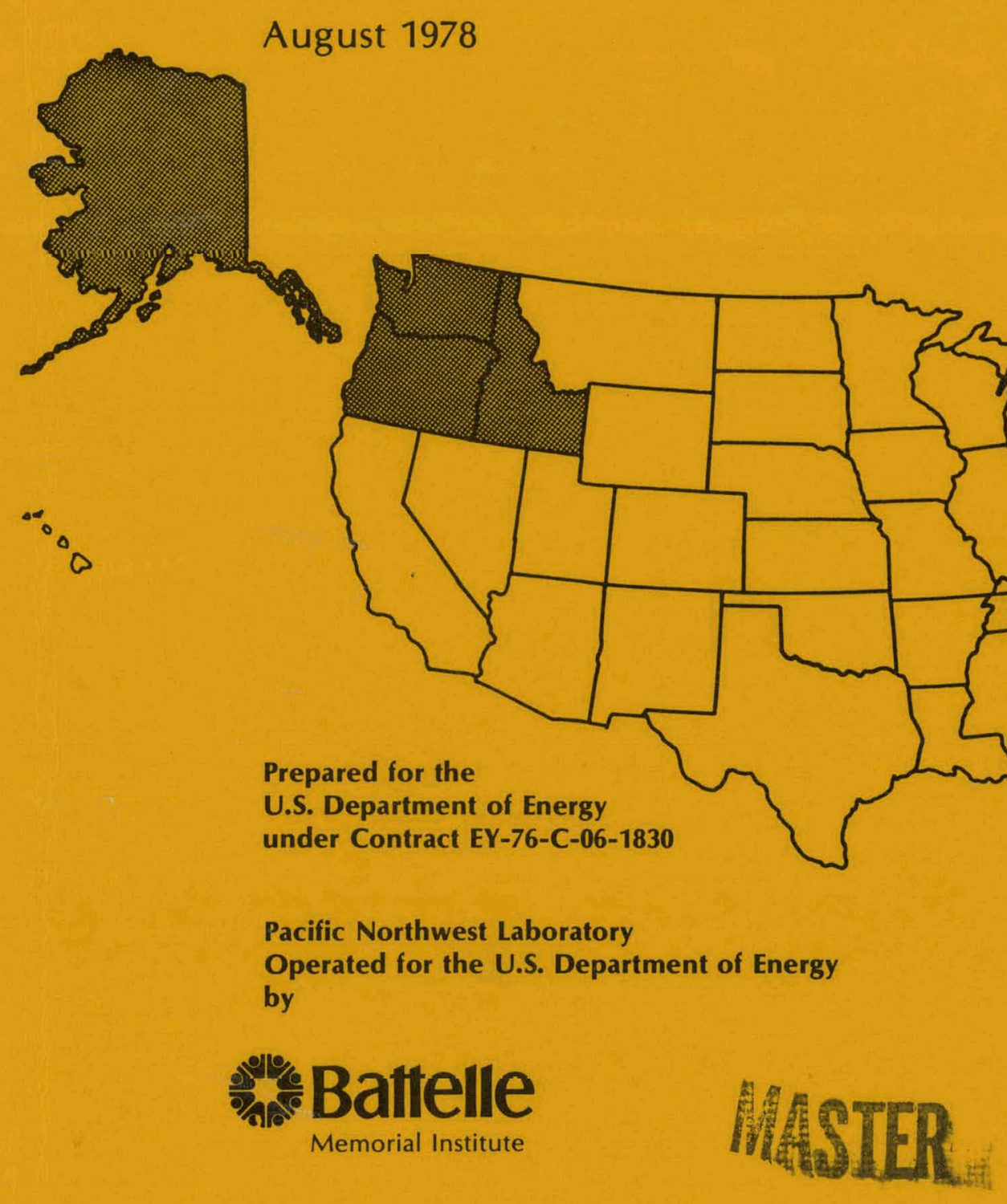




\section{DISCLAIMER}

This report was prepared as an account of work sponsored by an agency of the United States Government. Neither the United States Government nor any agency Thereof, nor any of their employees, makes any warranty, express or implied, or assumes any legal liability or responsibility for the accuracy, completeness, or usefulness of any information, apparatus, product, or process disclosed, or represents that its use would not infringe privately owned rights. Reference herein to any specific commercial product, process, or service by trade name, trademark, manufacturer, or otherwise does not necessarily constitute or imply its endorsement, recommendation, or favoring by the United States Government or any agency thereof. The views and opinions of authors expressed herein do not necessarily state or reflect those of the United States Government or any agency thereof. 


\section{DISCLAIMER}

Portions of this document may be illegible in electronic image products. Images are produced from the best available original document. 


\title{
NOTICE
}

This report was prepared as an account of work sponsored by the United States Government. Neither the United States nor the Department of Energy, nor any of their employees, nor any of their contractors, subcontractors, or their employees, makes any warranty, express or implied, or assumes any legal liability or responsibility for the accuracy, completeness or usefulness of any information, apparatus, product or process disclosed, or represents that its use would not infringe privately owned rights.

The views, opinions and conclusions contained in this report are those of the contractor and do not necessarily represent those of the United States Government or the United States Department of Energy.

\author{
PACIFIC NORTHWEST LABÖRATURY \\ operated by \\ BATTELLE \\ for the \\ UNITED STATES DEPARTMENT OF ENERGY \\ Under Contract EY-/6-L-Ub-183U
}
Printed in the United States of America
Available from
National Technical Information Service
United States Department of Commerce
5285 Port Royal Road
Springfield, Virginia 22151

Price: Printed Copy $\$$

*; Microfiche $\$ 3.00$

- NTIS

$001-025$

$\begin{array}{ll}001-025 & \$ 4.00 \\ 026-050 & \$ 4.50\end{array}$

$051-075 \quad \$ 5.25$

$076-100 \quad \$ 6.00$

$101-125 \quad \$ 6.50$

126-150 \$7.25

$151-175 \quad \$ 8.00$

$176-200 \quad \$ 9.00$

$201-225 \quad \$ 9.25$

$226-250 \quad \$ 9.50$

251-275 \$10.75

276-300 \$11.00 
A SOCIAL IMPACT ASSESSMENT AND MANAGEMENT METHODOLOGY USING SOCIAL INDICATORS AND PLANNING STRATEGIES

Marvin E. 01 sen

Martha G. Curry

Marjorie R. Greene

Barbara D. Melber

Donna J. Merwin

Battelle Human Affairs Research Centers

August 1978

Prepared for

the U.S. Department of Energy

under Contract EY-76-C-06-1830

Pacific Northwest Laboratory

Richland, Washington 99352 
THIS PAGE

\section{WAS INTENTIONALLY}

LEFT BLANK 


\section{PREFACE}

Preparation of this report was funded by the U.S. Energy Research and Development Administration ${ }^{(a)}$ as part of its Pacific Northwest Regional Assessment Program. Parts I and II were written by Marvin 01sen, with the assistance of Barbara Melber and Donna Merwin. Part III was written by Martha Curry and Marjorie Greene. The main features of the impact assessment and methodology presented in Part II were previously described in an earlier report (01sen and Merwin, 1976).

(a) The U.S. Energy Research and Development Administration was assimilated into the U.S. Department of Energy on October 1, 1977. 
THIS PAGE

\section{WAS INTENTIONALLY \\ LEFT BLANK}


PREFACE. . . . . . . . . . . . . . . . . . . .

I. INTRODUCTION . . . . . . . . . . . . . . . . . . . 1

MEANING OF SOCIAL IMPACTS". . . . . . . . . . . . . . 1

THEORETICAL MODEL. . . . . . . . . . . . . . . . 3

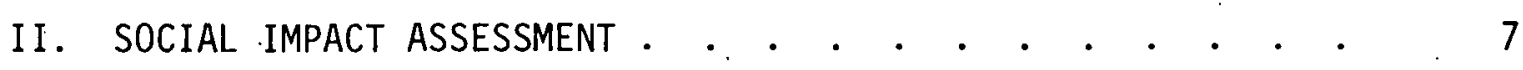

THE IMPACT ASSESSMENT PROCESS. . . . . . . . . . . . . . . 7

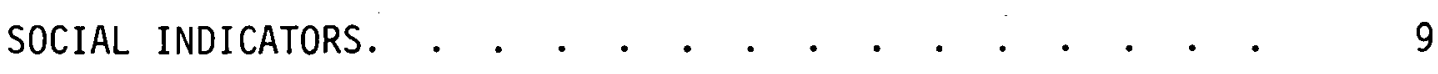

QUALITY OF SOCIAL LIFE . • . . . . . . . . . . . . .

SUBJECTIVE EVALUATIONS . . . . . . . . . . . . . . . . . . 18

TECHNIQUES. OF IMPACT RESEARCH. . . . . . . . . . . . . 21

TECHNIQUES OF IMPACT FORECASTING.

Trend Extrapolation . . . . . . . . . . . . 27

Standardized Multipliers. . . . . . . . . . . 28

System Models . . . . . . . . . . . . . . 30

flow Charts. . . . . . . . . . . . . . . 31

ASSESSING POTENTIAL SOCIAL IMPACTS . . . . . . . . . . 34

III. SOCIAL IMPACT MANAGEMENT .. .

THE IMPACT MANAGEMENT PROCESS. . . . . . . . . . . . . . 39

COMPONENTS OF THE IMPACT MANAGEMENT PROCESS . . . . . . . 40

Existing Functional Capabilities . . . . . . . . 40

Existing Planning and Management Capabilities. . . . 40

Community Goals. . . . . . . . . . . . . . 40

Impact Amelioration Requirements . . . . . . . . 41

Planning and Management Needs ... . . . . . . . 41 
Potential Planning and Management Resources . . . . 41

Recommended Planning and Management Strategies . . . 42

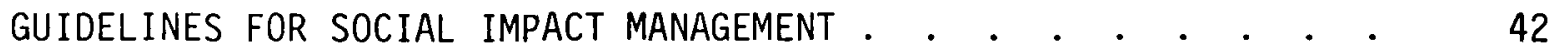

1. Involve the Public In the Community Political.
Process. . . . . . . . . . . . . 44

2. Develop and Implement a Comprehensive Community Planning Process.......... . . . . . 46

3. Develop and Maintain an Accurate and Current Information Base . . . . . . . . . . . 46

4. Initiate a Cooperative Working Relationship with the Develnper . . . . . . . . : . . 47

5. Identify Impacts Early . • . . . . . . . : 51

6. Find and Obtain Adequate Resources . . . . . . 52

7. Establish Inter- and Intragovernmental Coordination and Communication with all Affected Agencies . . . . . . . . . . . . 54

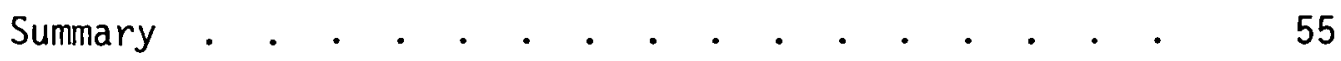

RELATIONSHIPS BETWEEN PLANNING AND COMMUNITY DECISION MAKING • . . . . . . . . • . • . . . . . 55

Role of Local Planning . . . . . . . . . . 56

Regional Planning . . . . . . . . . . . . . 57

State Planning . . . . . . . . . . . . . 57

Sulliliary • • • • • • • • • • • • • • • • 57

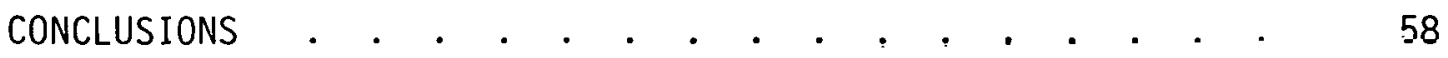

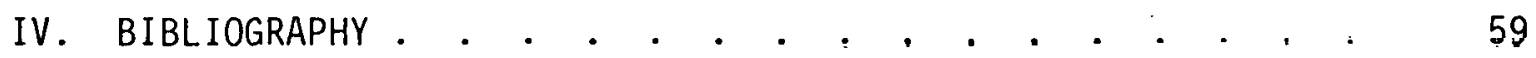

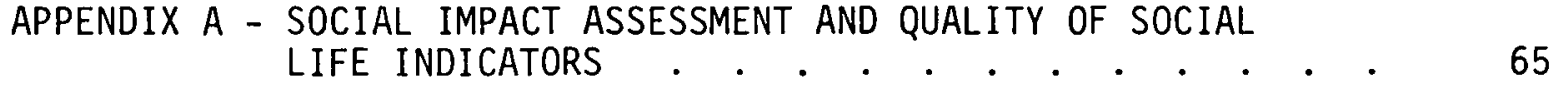

APPENDIX B - FLOW CHARTS - • . . . . . . . . . . . . 75 


\section{A SOCIAL IMPACT ASSESSMENT AND MANAGEMENT METHODOLOGY USING SOCIAL INDICATORS AND PLANNING STRATEGIES}

\section{INTRODUCTION}

\section{MEANING OF SOCIAL IMPACTS}

The scope of environmental impact statements prepared during the past few years has steadily expanded to incorporate all aspects of the social as well as the natural environment, including demographic, economic, social, political, and cultural conditions. Broadly conceived, social impacts are alterations in people's living conditions that occur in conjunction with a new policy, program, or project, and that 1) are in addition to all other concurrent changes produced by other factors, and 2) are seen by those affected as significant social events. Since any social environment is constantly changing, the crucial problems in analyzing social impacts are to identify those social alterations that are a direct or indirect result of the specific action under examination, apart from all other events and changes, and to determine which of these alterations are having significant social effects on the people involved.

Three features of this conception of social impacts are especially noteworthy. First, although impacts are often thought of as undesirable or detrimental in nature, they may also be desirable or beneficial, so that impact assessments must always explore the full range of both positive and negative consequences of the action being analyzed.

Second, although impacts are often described as caused by prior intervening innovations, in reality they always interact with their original causes in a reciprocal process, either immediately or after some time lag. Hence the above definition speaks of impacts as occurring in conjunction with an innovation, rather than resulting from it. For instance, the interactive process between a construction project and its impacts, as well as other related factors that must be examined in any thorough social impact analysis (SIA), has been diagrammed and described by wolf (1974:11) in the following manner: 


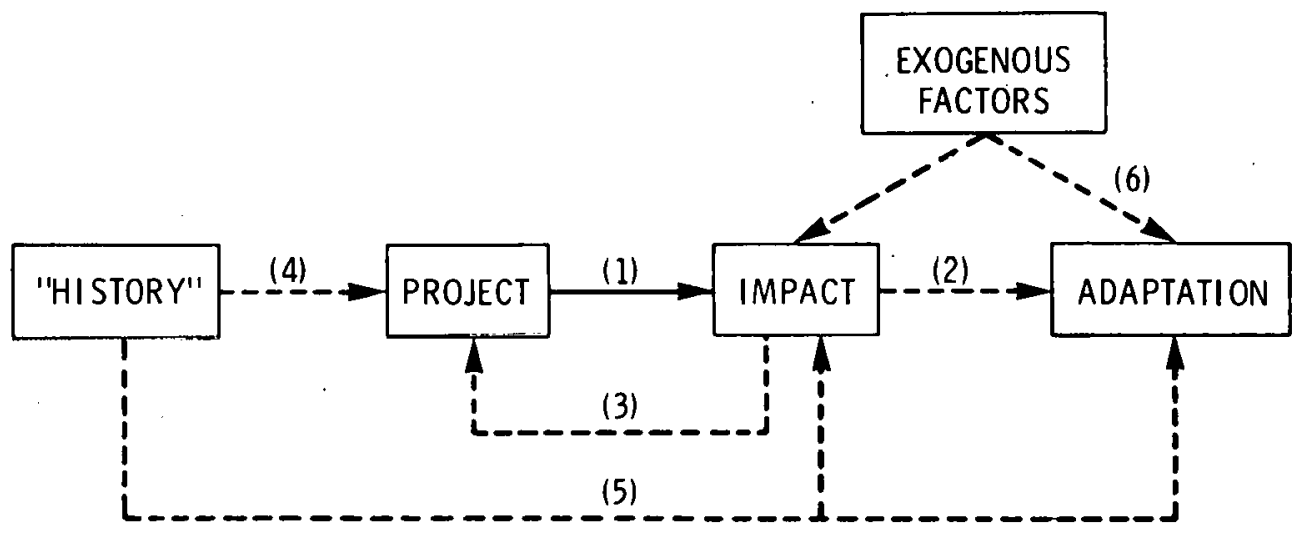

FIGURE 1. Interactive Nature of Sncial Impact Assessment.s

The direct impact 1) is a deformation in the state variables describing initial conditions, but if analysis were to end there it would severely distort the reality situation of SIA. The continuing effects of readjustment and adaptive change represent a sort of "feed-forward" 2). We can further hypothesize a differential social responsiveness on the part of impacted units. Conversely, in the planning phase the direct impact may result in a kind of "reaction formation" which impinges on project planning itself 3 ), in the form of public opposition and plan modification. Moreover, the project itself may be regarded as the social effect of a social cause--its "history" as a prospective solution to preexisting concerns, problems and issues residing in the affected area 4 ), and this history conditions public receptiveness at the points of impact and subsequent adaptation 5). Finally, the intrusion of exogenous variables 6 ), whether random or systematic, compounds the problem of attributing measured effects to planned interventions.

Third, the purpose of social impact assessment is to enable policy makers to anticipate and plan for potential impacts before they occur, and then act to prevent or mitigate undesired impacts. As a result of such impact management efforts, some predicted impacts never actually occur.

Thus far, virtually all social impact assessments have been made on an ad hoc basis, without any standard methodology. Two serious consequences of this condition have been 1) a lack of continuity among social impact assessments that would render their findings comparable or cumulative; and 2) few attempts to perform social impact research on current or completed projects 
to ascertain their actual social consequences. There is, consequently, a pressing need to develop a standardized methodology for conducting social impact assessments.

Another critical limitation of most previous social impact studies has been their failure to consider planning and management strategies that might prevent, mitigate, or cope with the impacts produced by a new policy, program, or project. Although relatively little is presently known about such strategies, a complete analysis of the total impact process must clearly give considerable attention to impact management procedures. Hence a second pressing need is for extensive exploration of this "forgotten half" of the impact process.

The purpose of this report is to propose a new methodology for performing social impact assessment and management studies that meet these current needs by emphasizing standardized.social indicators and social planning techniques. We refer to our approach as the Social Impact and Planning (SIP) method of social impact assessment. A preliminary version of this methodology was described in an earlier paper (01sen and Merwin, 1976), but it has since been substantially revised. The basic outline of this methodology is essentially complete, although it will be extensively elaborated and refined in the future on the basis of experience gained through field applications.

\section{THEORETICAL MODEL}

The methodology proposed here is grounded in the theoretical perspective of human ecology, which views mankind as inexorably dependent on the natural environment. Human social life is always constrained and shaped by the basic factors of natural resources, population characteristics, material and social technology, and the economic order which satisfies peoples' sustenance needs (Micklin, 1973). To this ecological perspective we add two further assumptions:

- Collective social activities are generally aimed at the attainment of goals that reflect the values and interests of the participants, so that social impact assessments must reflect both the ecological conditions prevailing in an area and the values, interests, and goals of the local residents. 
- A community can be viewed as a problem-solving social system, in which 1) challenges such as new environmental or technological conditions initially disrupt existing social conditions and practices, which

2) create temporary problem situations, which in turn 3) generate collective responses to cope with these problems, which finally 4) act back (as either positive or negative feedback) on the initial disruptive conditions.

These perspectives and assumptions are reflected in the General Social Impact Model shown in Figure 2, which provides a theoretical framework for our Social Indicator and Planning methodology. The principal inputs to this model are such intervening innovations as growing reșource scarcities (e.g., oil or water depletion), governmental policy decisions (e.g., emphasis on solar energy, limiting economic growth), or technological development projects (e.g., nuclear energy centers, water reservoirs). Regardiess of the precise nature of the intervening innovation, however, it can be expected to produce several direct and relatively immediate changes in the population and the economy of the area affected by the innovation. And since these two realms are normally quite interrelated, any change in one of them will likely also produce a corresponding change in the other. These direct effects will in turn lead to numerous indirect or secondary changes in the social structure of the affected area or community, in the provisions of all kinds of public services, and in the social well-being of that community. The extent to which all these changes produced by the innovation are experienced as significant social impacts by the affected people will depend primarily on 1) their existing social, economic, and political conditions, 2) their prevailing values, interest, and attitudes and 3) their general satisfaction with the community as a place in which to live. (This latter factor is in turn highly influenced by the economic conditions, public services, and social well-being of the community, as well as people's values, interests, and attitudes.)

The social impacts experienced by the affected people as a result of changes produced in their community by the innovation can have two kinds of effects: 1) They can act as feedback messages to that innovation, which may then be altered in some manner to take account of the social consequences it 
INPUTS

OUTPUTS

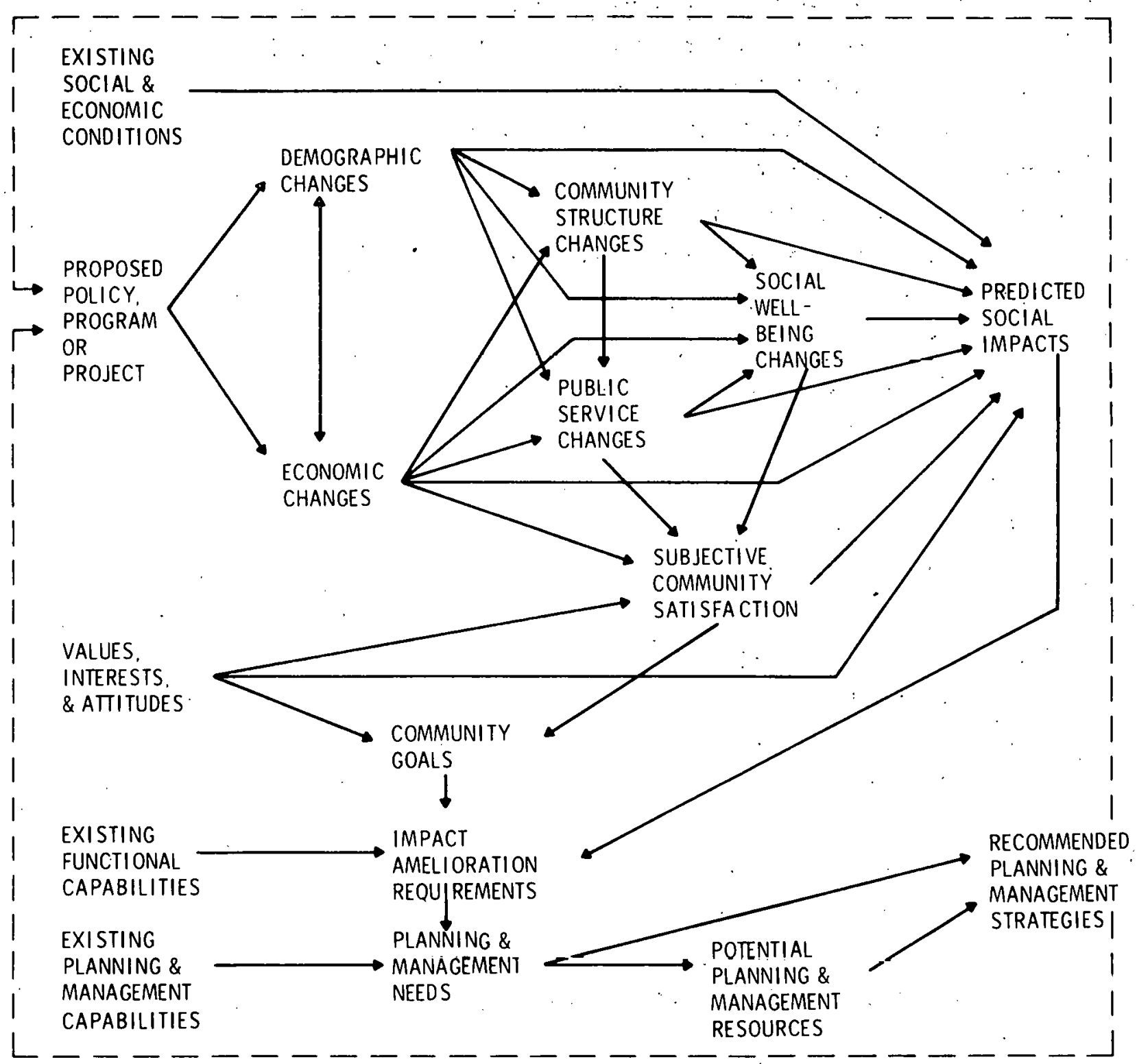

FIGURE 2. General Social Impact Assessment and Management Model

is generating. 2) They can initiate a social impact management process. In this latter case, the nature and extent of the impacts, in. conjunction with the existing functional capabilities of the community and its collective goals, determine the amelioration actions necessary to deal with these impacts. 
Community goals are shaped by people's values, interests, and attitudes, as well as their satisfaction with the current state of the community.) A community's amelioration requirements, considered in conjunction with its existing planning and management capabilities, determine the planning and management actions needed to cope with the anticipated impacts. These planning and management requirements, together with whatever planning and management resources are potentially available (such as federal funding programs), provide a basis for developing a set of recommended planning and management strategies to prevent or alleviate the expected social impacts. Finally, if these recommended strategies are enacted, they may alter either the nature and extent of the social impacts experienced by the affected people, and/or the initial innovation.

The geographical area impacted by an innovation--and hence the area to which this model applies--will obviously be greatly influenced by the nature and scope of the innovation. In general, however, most social impacts are experienced within the "functional community" that encompasses the innovation, although a large project may have some discernable impacts throughout a state or region. We therefore propose that the basic unit of analysis for social impact studies should be the "functional community," which may include two or more functionally interrelated towns or cities, as well as immediately surrounding rural areas. In practice, this will usually mean that data should be collected on a county basis. In urban areas the county usually encompasses the entire urbanized area, which avoids introducing unnecessary divisions between city and suburbs. With smaller cities, the county includes both the incorporated entity and the immediately surrounding rural areas that are economically dependent on it. And in rural settings, the county often contains several small towns that are functionally interrelated, as well as farms and other rural settlements. Moreover, counties are the basic units for which many demographic, economic, and other statistics are routinely collected by government. In this report we shall therefore speak of social impacts as occurring in a community, with the understanding that empiricaliy this refers to an entire county or multi-county area.

The remainder of this report is divided into two major parts, the first .. dealing with social impact assessment and the second with social impact management. 


\section{SOCIAL IMPACT ASSESSMENT}

\section{THE IMPACT ASSESSMENT PROCESS}

The purpose of a social impact assessment is to identify and measure the impacts that result from a specific innovation. Depending on when the analysis is conducted, an impact assessment can be described as either forecasting or research.

Impact forecasting is done before the innovation occurs to determine what social impacts it will probably create in the future if it is enacted, apart from the conditions that would likely exist at that future time without the innovation. This process of impact forecasting always involves considerable margins of error, since our predictions are at best informed estimates of future conditons. When properly done, however, they become vital inputs to decision-making and long-range planning.

Impact research is done after an innovation is already underway or has been completed to determine what social impacts it is having or has had, apart from the conditions that would have existed anyway if it had not been enacted. This process of impact research is essentially the study of ongoing social change processes, although it involves estimating the conditions that would have occurred without the innovation. Knowledge gained through such research provides the necessary factual basis for making future impact forecasts.

The total process of impact assessment (either forecasting or research) can be divided into the following four stages:

- Describing the social conditions existing in the affected community before the innovation--which we shall call time ${ }_{1}$.

- Determining the social conditions existing in the affected community at a later date--time ${ }_{2}$-without the innovation.

- Determining the social conditions existing in the affected community at time $_{2}$ with the innovation.

- Assessing which of the changes introduced by the innovation are significant enough to constitute either beneficial or detrimental impacts for the people involved, and evaluating the effects of these impacts on them. 
In all four stages, impact forecasting will differ somewhat from impact research, because of the differing time frames. Forecasting involves comparing present conditions with potential future conditions whereas research involves comparing past with present conditions. But the four stages are similar in both cases.

The essential purpose of any social impact assessment is to determine what changes--and hence what impacts--are created in a community by an innovation

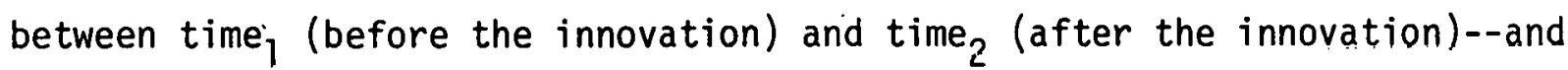
perhaps also at subsequent intervals of time $_{3}$, time 4 , etc. These innovationassociated changes and impacts must be carefully distinguished, however, from all other changes that have or will occur in the community from other causes. The time frame involved in this process is diagrammed in Figure 3.

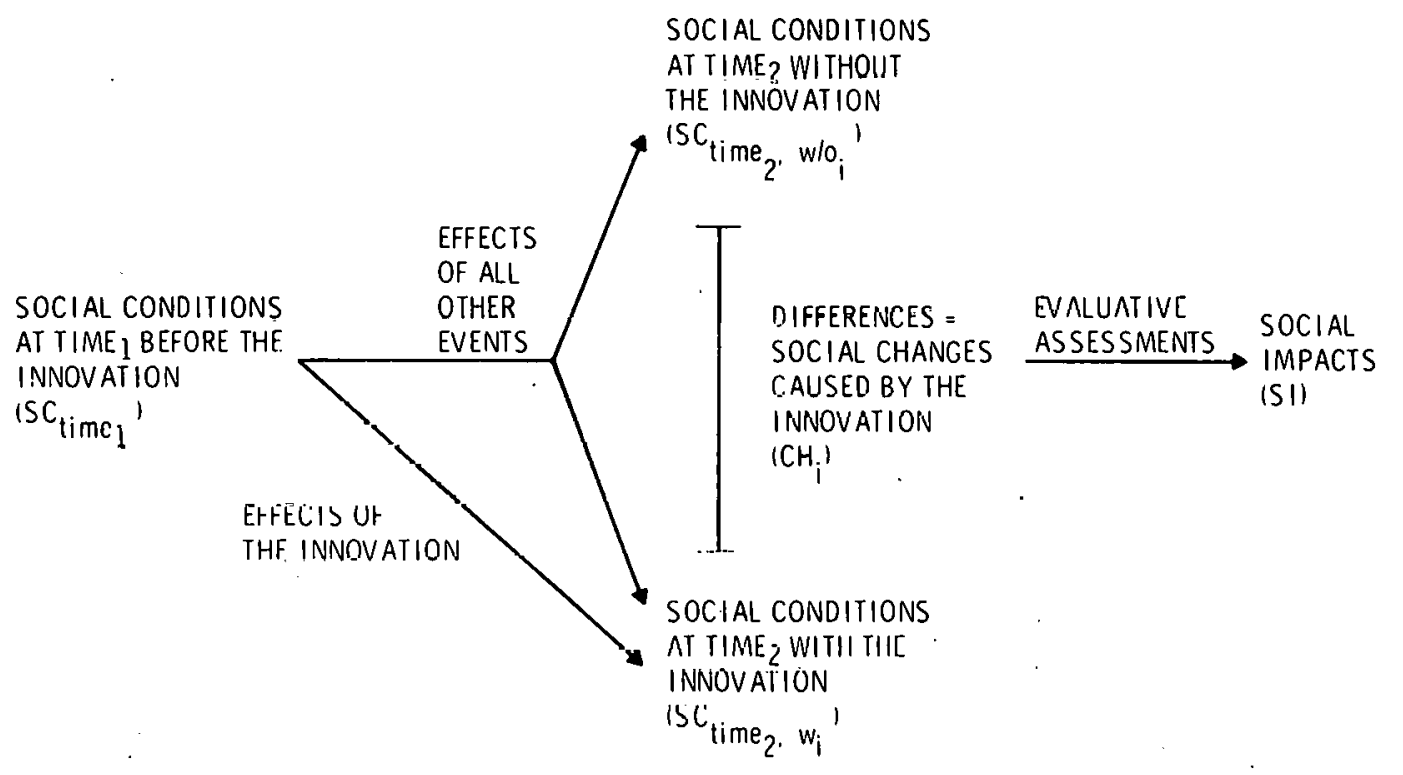

FIGURE 3. Social Impact Assessment Process 
In this diagram, the magnitude of the changes resulting from the innovation under investigation is determined by comparing the social conditions predicted in the community at time, without the innovation, with the conditions predicted or prevailing at time ${ }_{2}$ with the innovation:

$$
C H_{i}=\left(S C_{\text {time }_{2}}, w_{i}\right)-\left(S C_{\text {time }_{2}}, w / o_{i}\right)
$$

The significant social impacts associated with this innovation are then determined by evaluating the nature and importance of the various social changes.

\section{SOCIAL INDICATORS}

The social impact assessment methodology presented in this report uses sets of social indicators to measure both predicted and actual impacts of new projects or other innovations. Social indicators are standardized quantitative measures of specified social conditions that are collected periodically (usually annually) as a time series to describe both current conditions and ongoing change trends. The term "social" is used here in a generic sense to include all realms of human affairs--demographic, economic, organizational, political, and cultural--although a distinction is often made between economic and noneconomic (i.e., all other) indicators. Most commoniy, social indicators refer only to objective social conditions, and exclude such subjective phenomena as attitudes, perceptions, beliefs, and values, although these are sometimes inferred from the observed objective conditions.

Since the initiation of the "social indicator movement" with the publication of Bauer's (1966) Social Indicators, this methodological approach has been applied to measuring the attainment of national goals (Gross, 1967), social change (Sheldon and Moore, 1968), societal monitoring (Wilcox, et al., 1972), social theory development (Fox, 1975), and social system modeling (Land and Spilerman, 1975). The principal benefits of employing standardized, quantitative, time-series social indicators in these various contexts are to introduce greater empirical rigor, comparability, and temporal awareness into social science research. The social indicator approach has not been applied systematically to the processes of measuring social impacts, however. A proposal to 
use social indicators as measures of social impacts was put forth by Finsterbusch, et al., (1975), but their methodology consists of an elaborate "relevance tree" classification scheme in which the suggested indicators are not quantified.

We begin by dividing the total array of potential social impacts into the five sectors of Demography, Economy, Community Structure, Public Services, and Social Well-being that were shown in Figure 2. Each of these sectors is composed of numerous factors or characteristics, although the exact number and nature of the factors comprising a sector can vary depending on the purpose of the analysis. Based on a thorough review of the existing literature on social indicators and social impact assessment, we identifed between 8 and 12 factors in each sector--for an overall total of 50--that appear to be particularly relevant for assessing social impacts. For instance, the demographic sector consists of these 9 factors: population size, annual amount of population change, annual rate of population change, degree of urbanization, sex ratio, age structure, ethnic composition, educational attainment, and family status.

In most cases, each of the 50 factors could be measured with more than one empirical indicator. For instance, the quality of the educational system in a community might be measured with the indicators of 1) expenditures per pupi 1, 2) student-teacher ratio, or 3) scores on standard achievament. tests: These three alternatives illustrate what are sometimes called "input indicators," "thruput indicators," and "output indicators." We are usually concerned ultimately with final outputs of activities, so that output indicators are the most preferable. Unfortunately, these data are often nonexistent or inadequate. Conversely, the data necessary for input indicators are often readily available-usually as number of events per capita or annual expenditures per capita--but these data are generally only crude indicators of eventual outputs. Thruput indicators--often number of actions taken or people processed-are commonly of little interest in themselves (except to specialists in that area), but they are generally more indicative of final outputs than are input indicators, and the necessary data are also often available.

In selecting empirical indicators with which to measure each of our 50 factors, we followed four criteria: 
- Select only one indicator per factor. Although an argument can be made for using more than one indicator per factor in order to broaden the measurement base and lessen the chance of measurement error, multiple indicators produce two serious problems: 1) doubling or tripling datacollection costs; and 2) requiring some scheme for assigning weights to the various indicators of each factor. Since the easier a methodology is to use the more widely it will be employed, the first of these problems is a critical consideration. And since we have no empirical basis at the present time for assigning weights to all possible indicators (the common practice of simply adding them together has the affect of weighting them all equally), the second problem raises a serious barrier to the use of multiple indicators.

- Select indicators that are quantifiable, on an ordinal if not an interval scale. Qualitative descriptions may be more vivid and interesting to read than quantitative statistics, but they cannot be systematically compared or analyzed.

- Select indicators, as far as possible, for which data can be obtained from existing records or public officials in a community. If the analyst must collect primary data through interviews, questionnaires, controlled countings, etc., the cost and difficulty of using the methodology will rapidly increase. With a few of the indicators, some amount of primary data collection is inescapable, but we have avoided all indicators that would require a cross-sectional survey of the general population.

- Select ouput indicators if available, with thruput indicators as second choice and input variables as last choice.

Appendix A lists the 50 factors included in our methodology, arranged into the previously mentioned five sectors. For each factor, three pieces of information are listed: 1) the recommended empirical indicator for that factor; 2). the most likely source for obtaining the data for that indicator in a community; and 3) the current (1974) U.S. national average for that indicator, as a point of reference. 
To ensure that the data necessary for each indicator were available in at least one community, we used Seattlè, Washington, as a test case, and (with a few exceptions) selected only indicators that were obtainable from existing public sources. In smaller communities and rural areas, however, it may be necessary to omit some of these indicators for which data are not available. The intended unit of analysis for all these indicators is the county, so that if any data are available only for urban places, it will be necessary to extrapolate those figures (on a per capita basis) to the rest of the county.

A common practice, when using numerous social indicators, is to combine them into sets and compute a single index score for each set. For example, the indicators for all nine demographic factors listed previously might be combined in some manner to construct a single "demographic index" for a community. Two arguments can be given for not doing this, however: 1) it usually involves combining noncomparable items ("apples and oranges") in a single index, which then loses all intutitive meaning; and 2) it involves assigning valuative weights to the various indicators--either treating them all equally (all weighted " $1 "$ ) or giving them different weights according to some criteria of importance. If commonly accepted weights were available for all these social indicators, use of a weighting procedure would considerably enhance the value of this methodological approach. At the present time, however, no standard weights have been established to indicate the relative importance of these various social indicators. Consequently, composite index scores composed of "unweighted" indicators are actually weighting them all equally. We therefore recommend that each factor be separately measured and reported. and tht. the temptation to construct index scores be continually resisted.

Actual procedures for utilizing these sncial indicators when performing social impact forecasting or research are described in subsequent sections. In general, however, the principal benefits of this proposed social indicator methodology for social impact assessments are that it would 1) establish uniformity in the kinds of data that are collected in all impact assessments; 2) express these data in standardized quantitative measures that are 
comparable across communities and time periods; 3 ) simplify the process of forecasting future social conditions, both with and without a proposed innovation; and 4) encourage more rigorous research to monitor the actual social consequences of ongoing activities. The main limitation to this methodology is the difficulty of obtaining the necessary empirical data, which are often challenging to locate or are recorded in an unappropriate manner. This limitation should diminish, however, as researchers become more familiar with how and where to locate these data in existing records, and as public officials come to recognize the need for compiling such information regularly and in a usable manner.

QUALITY OF SOCIAL LIFE

Proponents of the use of social indicators for public policy formation have frequently assumed that these measures provide objective, value-free tools for measuring existing social conditions. The classic example of this is the assumption that the Gross National Product provides an objective measure of the size of the national economy, uncontaminated by any human values. Actually, several critical value assumptions are built into the construction of this indicator, including the ideas that housework done in one's own home does not contribute to the national economy, and that funds spent first to produce a product that pollutes the natural environment and then to el iminate that pollution both contribute to the overall GNP.

In a similar manner, value assumptions are imbedded in several aspects of the social impact assessment process and the use of social indicators. Perhaps the clearest example of this in most prior social impact studies has been the use of a cost-benefit analytical framework, borrowed from economics. In addition to the fact that many social phenomena cannot be specified in monetary terms, several critics of this technique have pointed out that 1) what is beneficial to one set of people may be detrimental to another, 2) those who receive the benefits of a program or project are often not those who pay its costs, and 3) there is usually a critical time lag between the imposition of immediate costs and the realization of long-term benefits (Dunning, 1974:61). More generally, since straightforward balancing 
of social costs and benefits is rarely possible, any evaluation of the significance and seriousness of anticipated social impacts is always affected by one's social values. As a consequence, use of the cost-benefit format in social impact assessments has often resulted in environmental impact statements designed to demonstrate that the benefits to be gained from a proposed project will certainly outweigh the expected costs, rather than to ascertain the full nature and extent of the probable impacts (Wolf, 1974:9).

Social values also pervade the use of social indicators. The initial selections of dimensions to be measured and of indicators with which to meassure them involve numerous decisions about what factors and information are important for social life. For example, why do we usually examine the school facilities but not the number of bars in a community? More subtle are the assumptions we make about the direction of measurement with all indicators. For instance, we commonly assume that extensive social conflict is detrimental to a community, although many social scientists have shown that conflicts can (under certain conditions) have many beneficial consequences. In short, since values permeate the entire process of social impact assessment and the use of social indicators, social researchers using these techniques must strive to be consciously aware of the value assumptions they are making.

By themselves, social indicators are meaningless. They acquire meaning and relevance for social impact assessment only when placed in a broader valuative context. In other words, indicators are only measures of conditions that researchers or the public believe should be measured. The ultimate goal of social impact assessments is to protect or enhance the quality of social 1ife. Unfortunately, this "quality of life" has no commonly accepted meaning, beyond the vague notions of "public well-being" or "the general welfare." Nevertheless, all images of quality of social life refer in one way or another to what people believe is important in their lives. Consequentiy, whatever contributes to the quality of social life for a group of people is ultimately determined by them, and not by analysts, experts, or officials. This determination will always be thoroughly infused with normative values concerning what is desirable and undesirable in social life. 
The emphasis placed on quality of social life in recent years has reflected a growing public awareness that economic growth, by itself, does not necessarily contribute to the overall quality of human social conditions. As expressed in one government document: "Although the literature offers no consensus on a Quality of Life definition, a clear consensus does exist regarding the importance of the concept. People in business, in government, and in the universities are rethinking the old tendency to equate a rising GNP with national well-being. It is recognized that the paradox of economic indicators continuing to progress (rising income, increasing employment) in the face of growing discontent (ghetto violence, campus strife, street crime, alienation, and defiance) must be addressed" (U.S. Department of Health, Education, and Welfare, 1969).

Despite the widespread attention given to conceptualizing and measuring quality of life in recent years (Perloff, 1969; Wilson, 1973; Booz-Allen Public Administration Services, 1973; Liu, 1975), this notion has not been incorporated into the methodology of social impact assessment. Although impact researchers have frequently assumed implicitly that their assessments should be grounded on some conception of the quality of social life, recent papers by Finsterbusch, et al. (1975) and 01 sen and Merwin (1976) seek to make this linkage explicit by stipulating that the express purpose of using social indicators is to determine how closely existing or predicted conditions correspond to desired quality of life criteria. Because their concern is with social impact assessment, they exclude technological and natural environmental factors and refer only to the quality of social life in the impact area.

A11 of the 50 social indicators listed in Appendix A were selected because they affect the quality of social life in a community in some manner. More precisely, however, 25 of these indicators appear to be particularly crucial determinants of the quality of social life. These "quality of social life indicators" are indicated with an asterisk $(*)$ in the appendix. Analysts using this methodology will presumably want to give special attention to these 25 designated indicators, although the final determination of which factors contribute the most to the quality of social life in any particular community can only be made by considering the preferences of local residents. 
When social indicators are seen as measures of the quality of social life, they quickly become infused with valuative meanings. That is, the current level of an indicator, as well as its direction and rate of change through time, are evaluated as either desirable or undesirable according. to the desired goal for that factor. For example, if the desired goal for the sex ratio were 1.00 (equal numbers of males and females), and if the current level were 1.10 (110 males per 100 females) and rising due to an influx of single male workers, this would be judged an undesirable condition that should be altered. The desired goal for each quality of social 1 ife indicator may be specified either by a group of qualified experts (for example, the ideal ratio of 0.8 primary care physicians per 1,000 population established by the American Medical Association), or by the public as a whole (for example, a sex ratio of 1.00). With some indicators, the desired goal may be simply as high or as low a figure as possible (for example, average family income, or the number of violent crimes per capita, respectively), while in a number of other cases there is an upper or lower limit beyond which further increases or decreases would be meaningless (for example, governmental revenues sufficient to provide all desired governmental services, or a divorce rate that reflected only irreconciliable marital problems). With many of the indicators, however, the desired goal is a purely subjective judgment that can only be determined by currently prevailing cultural values (for example, the desired rate of economic growth, or expenditures per capita for public recreational facilities).

The purpose of establishing these desired goals, regardless of how they are determined, is to provide ideal criteria against which current or expected social conditions can be compared. The evaluation of the projected changes called for in Stage 4 of the social impact assessment process can then be based on clearly specified criteria. These criteria will necessarily change through time and vary from one setting to another, but at the very least they remove the process of evaluating impacts from the realm of purely arbitrary supposition. 
No desired goals are given for any of the indicators in Appendix $A$, since we have no grounds at present for making these determinations for most of the indicators. Eventualiy it may be possible to specify desired goals for many of these indicators on the national level, but that effort will require extensive research and testing. Moreover, in any particular community it will still be necessary to ascertain which of the national standards are accepted there and which are rejected in favor of unique local standards.

When a desired goal has been established for a social indicator, a standard score can be calculated for that indicator which specifies the degree to which its observed condition approaches its desired goal (either below or above it). These standard scores are computed with the following formula:

$$
\text { SIS }=1-\left|\frac{M S-D G}{D G}\right|
$$

where SIS = standard indicator score, MS = measured indicator score for an observed condition, $D G=$ desired goal for that indicator, and the absolute value of this ratio is utilized. The resulting standard indicator scores have a maximum possible value of 1.00 when the measured score equals the desired goal. In most cases the minimum possible standard score is 0 , but if the measured score can be a negative number (as in the case of a negative growth rate), then the resulting standard indicator score could be any negative number. Once measured indicator scores have been converted into standard scores in this manner, they can be combined into composite indexes since they are all being expressed in a common unit (percent deviation from a desired goal)--provided that the problem of assigning relative weights to each of the indicators has been resolved in some way.

Another advantage of using quality of social life indicators to measure social impacts is that the process of evaluating the effects of anticipated changes on the quality of social life can be separated into many relatively small segments. The usual procedure in past social impact assessments has been to gather all the necessary data without explicitly considering any 
valuative or quality of life issues, and then make a single evaluative decision concerning the overall costs and benefits of the ancitipated innovation. In contrast, this social indicator approach places much of the evaluation process in the initial tasks of 1) selecting social indicators to measure relevant social conditions, and then 2) comparing these measured indicator scores with the desired goals of the affected people. As emphasized previously, these judgments will necessarily reflect differing conceptions of the quality of social life, but since each decision pertains only to a 'fairly small and delineated facet of social life, each one can presumably be made with considerably more rationality than can a single global evaluation.

\section{SUBJECTIVE EVALUATIONS}

Thus far we have discussed only objective indicators as measures of the quality of social life. Subjective evaluations enter the impact assessment process in at least three ways, however: 1) as sets of cultural values prevailing in a community; 2) as attitudes of satisfaction or dissatisfaction with conditions in the community; and 3) as assessments of which changes produced by an innovation constitute serious social impacts.

Stage 1 of the impact assessment process--describing the conditions existing in the community at time, prior to the innovation--must include the construction of a value profile for that community. A value profile identifies the major values prevailing in a community, and tells what proportion of the population or what segments of the population hold that value to be important for the community. Although this analysis can include whatever values are espoused by the residents of the community, it should definitely cover certain sets of values that are particularly relevant for evaluating social impacts, such as the desirability or undesirability of both demographic and economic growth, desired composition of the local population, the preferred economic base and income level of the community, the role and importance of community organizations in public life, preferred housing types, the responsibilities of government in providing necessary social services, and the level of concern for equity, safety, and other social problems. 
In addition to exploring these basic community values, it is also necessary, when using this proposed social indicator methodology, to obtain value judgments concerning each indicator. For all 50 indicators, the analyst must ascertain how important the local residents believe each one is in determining the quality of social life in that community. . This may likely involve only a crude categorization such as "not important," "somewhat important," and "very important," but the results will tell the analyst which factors are irrelevant for that community and which are crucial components of its quality of social life. In addition, for those factors which are critical determinants of the quality of social life (the 25 designated indicators in Appendix $A$, as modified by local values), the analyst must also ascertain the most widely shared ideal goal for that factor.

The usual procedure for obtaining these data on community values is to conduct a survey--using either written questionnaires or personal interviews-covering a random sample of the total adult population of the community. Unfortunately, however, surveys entail considerable effort and expense if they have adequate size samples and are constructed and tested according to professional standards. Consequently, two alternative procedures for constructing a community value profile may be employed. Neither is as expensive or time consuming as a cross-sectional survey although both entail greater risks of bias.

One of these techniques is to identify and interview a small set of "key informants" who are knowledgeable about local values and goals. Some of these infuriliants are selected on the basis of thcir occupations (for example, the local newspaper editor, a labor union leader, the president of the Chamber of Commerce); some are selected as spokespersons for minorities and other segments of the population (for example, a leader of the black community, a prominent religious leader, an advocate of women's concerns); and some are nominated by others in the community as local opinion leaders. The principal disadvantage of this "key informant" approach, relative to a sample survey, is that it is critically dependent on the accuracy of the respondents' perceptions of the values of others. This disadvantage can be circumvented, however, to the extent that the informants selected for the 
study are persons who function in the community as "communication gatekeepers." These informants would be asked to respond to a set of standardized interview questions, but would also be encouraged to comment freely on their perceptions of prevailing community values and goals.

The other alternative procedure is to interview a small (maximum of 100) sample of local inhabitants, using relaxed sampling and interviewing standards. For example, the initial sample might be randomly selected from the telephone directory, but unlimited substitution would be permitted to compensate for persons who could not be reached or who refused to participate. And instead of using precisely specificed questions, this approach might employ a "semistructured, variable format" interview guide consisting of a list of broad topics that are to be covered sometime during the interview, according to the discretion of the interviewer. This procedure does not produce quantitative data that can be statistically analyzed, but the comments and remarks obtained in these interviews can yield rich insights into the values and goals of the local population.

Subjective considerations also enter the social impact assessment process as attitudes of satisfaction or dissatisfaction with various aspects of the local community. Whereas a value is a shared ideal that people would like to see realized if possible, satisfaction is an individual judgment based on the degree to which existing conditions correspond to personal ideals. Personal satisfaction--with one's community, neighborhood, housing, job, family, and other realms of activity--is often a major component of the quality of social life (Andrews, 1974). Recent research on perceived satisfaction with one's community revealed that "most people are satisfied with their communities as places to live" (Campbell, et al., 1976:222). When asked ahnut sperifir community services, however, only about one-third of this national sample rated their schools, parks, police protection, streets and roads, and public transportation as "very good" (Campbe11, et al., 1976:223).

Individual satisfaction scores can only be obtained through personal interviews or questionnaires, but two considerations can limit the amount of effort and expense needed for this effort. First, because these items are quite simple and straighforward (for example, "How satisfied are you with 
this community as a place to live?"), they can be asked in brief telephone interviews that are easy and inexpensive to conduct. Second, because national data are available for many of these satisfaction items, the sample needed in any one community can be fairly small (unless it yields results that are widely discrepant from the national figures).

Finally, subjective evaluations always affect decisions about which predicted changes from an innovation will be significant enough to constitute social impacts for the affected community. This process will be discussed at length in a later section.

\section{TECHNIQUES OF IMPACT RESEARCH}

The principal reason for developing and utilizing quality of social life indicators is to provide standardized quantitative measures of social change. In the case of social impact assessment, we are concerned with changes produced by a new policy, program, or project. Our ultimate goal is to be able to forecast, in advance, the changes likely to result from a proposed action. To be able to do that, however, we must acquire extensive knowledge of the effects--both direct and indirect--that various kinds of innovations actually have on communities. That knowledge comes primarily from social impact research on past and on current innovations. We propose, therefore, that the same set of social indicators be used for both impact research and impact forecasting, so that the data obtained from studies of past and current events will be directly applicable to forecasting proposed future events.

Research on past events is convenient, since all of the resulting changes have already occurred and can be studied without any time delays. If the data are available, the researcher simply obtains measures of the various social indicators at some point prior to the innovation (time ) and at one or more points subsequent to it ( time $_{2}$, time $_{3}$, etc.) and compares their differences. A major limitation to such research, though, is that the necessary data are often no longer available from the past, or are not recorded in the form required by the standardized indicators. Consequently there is a pressing need for numerous ongoing studies of current programs and projects that will record their social effects as they occur. This kind of ongoing research, or social impact monitoring, begins with an initial round of data collection 
before the innovation begins, and continues through several subsequent rounds of data collection--usually at yearly intervals--during the existence of the program or project. The main disadvantage of this approach is that it takes several years to complete a study, but the data obtained in this manner will usually be much more adequate and accurate than data obtained from retrospective studies.

As diagramrled in Figure 3 (p. 13), social impact research studies must collect at least three sets of data for all relevant social indicators:

1) at time ${ }_{1}$ before the innovation, 2) at time ${ }_{2}$ without the innovation, and 3 ) at time ${ }_{2}$ with the innovation. (The researcher may likely want to continue collecting data at time 3 , time $_{4}$, etc., both with and without the innovation, but conceptually this process would be identical to data collection at time ${ }_{2}$. ) Obtaining baseline measures for the various indicators at time ${ }_{1}\left(\mathrm{SC}_{\text {time }_{1}}\right.$ ) is relatively straightforward, provided the necessary data are available from either historical or current records. Similarly, collecting subsequent measurements of the indicators at time ${ }_{2}$ (and time $_{3}$, etc.) with the innovation ( $\mathrm{SC}_{\text {time }_{2}, w_{i}}$ ) is simply a matter of monitoring ongoing conditions in the affected community.

The major difficulty in conducting social impact research is to estimate the conditions that would exist in the community if the innovation had not occurred $\left(S C_{t_{i m e}}, w / o_{i}\right)$, since these data are recessartly hypothetical. Ihere are three main ways to estimate these figures, all of which provide at best only crude approximations:

- If time trends can be established for the various indicators during the years preceding time ${ }$, these trends (whether they be linear, curvilinear, exponential, etc.) can be extrapolated to time ${ }_{2}$ with fair accuracy, especially if the time period involved is not too great.

- The county being studied can be matched (on as many variables as possible) at time, with another county not experiencing the innovation, and the figures for all the indicators at time ${ }_{2}$ in the control county taken as an estimate of ( $\left.\mathrm{SC}_{\text {time }_{2}}{ }^{\mathrm{w} / \mathrm{o}_{i}}\right)$ in the county being studied. 
- The relationship between the national means (or medians) for $\left(\mathrm{SC}_{\text {time }_{1}}\right.$ ) and the corresponding figures for the county at time ${ }_{7}$, in conjunction with national data for $\left(\mathrm{SC}_{\text {time }_{2}}\right)$, can be used to estimate $\left(\mathrm{SC}_{\text {time }}{ }_{2}{ }^{\prime} \mathrm{W} / \mathrm{o}_{\mathbf{i}}\right.$
in the county.

The impact research procedures described here are particularly relevant to the two categories of demographic and economic changes, which are directly affected by most innovations--especially large developmental projects--as shown in the general social impact model in Figure $2(p .6)$. As a hypothetical example of the reciprocal relationship between demographic and economic growth, assume that a project requires 1,000 workers for its construction. Of these jobs, 50 are filled by currently unemployed people in the area, 50 by people in the area who were not previously in the labor force, 300 by currently employed people in the area who switch jobs, and 600 by workers who migrate to the area on either a temporary or permanent basis. In addition, of the 300 jobs that are vacated by local residents going to work for the project, 50 are filled by previously unemployed persons, 50 by people not before in the labor force, and 200 by migrants from elsewhere. Each of the 800 migrating workers brings an average of 2.5 dependents, for a total project-related population growth of 2,000 people. This demographic growth then stimulates considerable secondary economic growth in the area (shopping service facilities for the growing population), which results in 800 additional new jobs in the community. Of these jobs, 500 are filled by current residents ( 350 by spouses of new project employees, 50 by previously unemployed persons, and 100 by people not previously in the labor.force), while the remaining 300 secondary growth jobs are filled by more migrants attracted to the community by its economic growth. With their 750 dependents, this adds 1,050 more people to the population. These additional residents then generate tertiary economic growth which adds 100 more jobs to the economy, etc. The total population growth of over 3,000 people described in this example would be a major addition to many communities, particularly small towns and rural areas. Moreover, if these new people differed significantly from the present residents--such as being predominantly blue-collar workers, or blacks, or single men--countless social changes could occur. 
Interwoven with these basic demographic trends are such economic processes as overall economic growth, varying rates of development in different sectors of the economy, resulting shifts in the distribution of wealth in the community, changes in. the tax base, rising costs of living, increased revenues from the state government, etc. From this full range of economic changes--interacting with demographic growth--would then likely come numerous secondary changes in the other three categories of community structure, public services, and social well-being. The researcher has more methodological flexibility in these latter three realms, however, since the causal linkages from demographic and economic conditions to community structure, public services, and social well-being (as well as the relationships existing among the factors within each of these categories) can be examined apart from any actual program or project. For example, the effects of rising income levels on the quality of medical care or the crime rate can be studied in almost any community.

The fundamental purpose of social impact research is to determine the patterns, directions, strengths, and lags of the causal relationships existing between an innovation and all affected social factors in a community, as well as all the interrelationships existing among these factors. That is, we need to determine--usually in the following order of increasing methodological sophistication--1) which factors are related to which other factors, 2) the causal directions of these relationships (both recursive and nonrecursive), 3) regression coefficients for the strengths of these relationships (both unstandardized b's and standardized betas), and 4) any temporal lag effects that occur in this causal process. Although much social science research is still dealing with the first of these tasks, and only recently has any significant headway been made on the second and third tasks, these limitations can at least temporarily be circumvented by specifying hypothetical patterns of causal relationships in one's theoretical model, and then asking the question: If these hypothetical sets of causal relationships did in fact exist, what kinds of impacts would a particular innovation have on the quality of social iffe in this community?

Eventually, however, sufficient research on social impacts and social change processes must be conducted to enable us to express in statistical 
terms precisely how changes in any given feature of a community will affect all other related community characteristics. Only when such regression coefficients become available and are interrelated within complex causal models will we be able to forecast the future changes likely to result from a proposed innovation with any degree of certainty.

\section{TECHNIQUES OF IMPACT FORECASTING}

The ultimate goal of social impact forecasting is to predict, as accurately as possible, the full range of social changes that will probably occur in a community as the result of an anticipated or proposed innovation. Thus far, the usual way of making these forecasts has been merely to project (usually on a linear basis) whatever trends were known to be occurring, and then to add onto them the expected (or guessed or estimated) effects of the innovation. In other words, both $\left(\mathrm{SC}_{\text {time }_{2}, w / \mathrm{O}_{i}}\right)$ and $\left(\mathrm{SC}_{\text {time }_{2}, w_{j}}\right)$ have been at best crude estimates with little basis in empirical knowledge. Moreover, this current practice does not consider the ways in which one change may affect others throughout the entire community. A few methods, such as cross-impact forecasting (Bloom, 1975), have been developed to identify these interrelated secondary impacts, but they rely heavily on subjective judgments by presumed experts.

In contrast, the benefits of our proposed social indicator methodology for impact forecasting are that: 1) it specifies precisely what factors and indicators are to be included in the forecast; 2) it designates which of these factors are especially crucial determinants of the quality of social $11 f e$, and delermines the public's desired goals for those factors; 3) it allows knowledge gained from impact research on past and current innovations to be directly applied to future forecasts, since the same indicators are used in both tasks; 4) when fully developed, it will enable social scientists to use dynamic system modeling to estimate all of the interrelationships occurring among all of the indicators, and hence greatly improve the scope and accuracy of their forecasts of expected future changes.

The procedures for making these future forecasts without and with the proposed innovation-- $\left(\mathrm{SC}_{\text {time }_{2}, w_{/ 0}}\right)$ and $\left.\mathrm{SC}_{\text {time }_{2}, w_{i}}\right)$--are basically similar. 
They both involve estimating future conditions from present and anticipated trends and events. For communicative convenience, in this discussion the term "expected" will refer to future conditions in a community without the proposed innovation but taking into account all other potential sources of future change, and the term "predicted" will describe those conditions that will likely exist if the proposed innovation is enacted. The differences between these expected and predicted sets of community conditions represent the social changes that are forecasted to result from the innovation.

The point of time in the future to which these forecasts pertain is determined largely by the expected duration of the proposed innovation. In the case of a rapid buildup and then decline of a construction labor force, the time frame might be only one or two years, while in other cases, the proposed action might continue to affect the social environment for many years or even permanently. Estimates of expected future conditions without the innovation usually treat the time span between the present and the designated forecast date as essentially uniform in terms of change trends. Predictions of future conditions with the innovation often become more complex, however, because many developmental activities--especially large construction projects--occur in relatively distinct phases which have quite different effects on the surrounding social environment. As an example, the construction phase of a nuclear power plant may require approximately 3,000 workers over a six-year period, but once the plant is operational it will require only 300 personnel for the next 30 years. Moreover, the construction workers are very different kinds of people from the technicians and enginecrs who operate the plant, To further complicate the picture, the work force required during the construction phase builds up to a peak during the first two years, remains level for about two years, and then drops steadily until the project is completed. Hence the forecasts for this project should be divided into at least three short construction phases and one long operational phase, with each phase having different effects on the social environment.

A forecast of future conditions in a community cannot possibly estimate with accuracy all the social changes that may occur there during the next 
several years, for many contingencies will remain unknown. An analyst attempting to make a useful forecast of future conditions, either without or with a proposed innovation, must therefore give primary attention to factors that have the greatest effect on the total community and are most significant for determining the quality of its social life. Our proposed list of 50 indicators (25 of which are identified as potential quality of social life determinants) is intended to provide a guideline for this selection process in all social impact assessments, although it may often be necessary to adapt this list to local conditions.

Methodological procedures for constructing forecasts of expected and predicted future changes can be divided into univariate and multivariate forecasts. A univariate forecast involves only one predictor variable or indicator at a time, whereas a multivariate forecast considers several predictor variables or indicators simultaneously. Forecasts can be classified as recursive, which utilize linear models without feedback loops, or nonrecursive, which incorporate feedback loops. Our present level of methodological development in this area normally limits us to recursive analyses, but as our methods and models become more sophisticated they must incorporate feedback loops if they are to approximate social reality.

The two main procedures for performing univariate forecasting of single factors are trend extrapolation and standardized multipliers. The former is most commonly used to estimate expected conditions without the proposed innovation, while the latter is more commonly used to predict changes that will likcly result from that innovation if it is enacted. Multivariate analyses, meanwhile, commonly utilize either system models or flow charts.

\section{Trend Extrapolation}

The best estimate of what any situation or factor will be like in the near future is often its most recent trend conditions. Under relatively stable conditions, trend extrapolation is a very useful technique for short-term forecasting. With this approach, the analyst obtains data on a particular indicator at the present time and at several points in the past. 
The observed trend is then extended into the future, either as a simple continuation or with some modifications if there are reasons to expect the trend to change. The longer the time frame the less confidence one can attach to the forecast, since cumulative stochastic probabilities steadily reduce the certainty of the expectations. Nevertheless, trend extrapolation-especially when it goes beyond simple linear models--is considerably more accurate than static extrapolation in which one simply assumes that today's immediate conditions will extend into the foreseeable future.

Trend extrapolation is particularly useful with population forecasting, and this method underlies the OBERS population estimates which the Department of Commerce has constructed for all Bureau of Economic Analys is areas throughout the United States. These OBERS estimates can be used to construct demographic forecasts for any region of the country at any point in the near future. A somewhat more detailed set of demographic forecasts, called MULTIREGION, is presently being developed by Oak Ridge National Laboratories. When completed they are expected to be superior to the OBERS data in that they will be subdivided into 37 economic sectors as well as by sex and fiveyear age cohorts, and will extend until the year 2020.

Standardized Multipliers

Given an estimated work force for a proposed project, several other conditions likely to exist in the surrounding area in the future can be estimated.using standardized multipliers. These are simply coefficients that express known relationships between two variables or indicators. For instance, if we know that the average family has 1.8 children, we can predict future housing needs for a given work force. And if we also know the expected age distribution of that projected population, our housing predictions can be even more precise by applying different multipliers to each age cohort.

Stenehjem and Metzger (1976) at the Argonne National Laboratory have recently calculated separate sets of demographic and economic multipliers for each county in the United States. They begin with an estimated labor 
force for a specific kind of project, determined largely by the nature of the technology involved. Three different multipliers (based on different initial assumptions) for estimating the number of additional jobs that will be created as a result of the project are then developed for each county. The sum of these direct and indirect employment estimates constitutes the total number of new jobs predicted for a county. The amount of in-migration required to fill these new jobs is determined primarily by the number of currently unemployed persons in the county and the number of estimated new entrants into the labor force each year. Two different "household factors" are then given for each county, to be used in estimating the number of dependents who will likely accompany each in-migrant (taking into account the fact that in many households both spouses will be employed).

As a simple example of this process, consider the following set of multipliers recently proposed by the Battelle Human Affairs Research Centers (1975) on the basis of the literature existing in 1975:

Project - Induced Population Growth

Primary work force $(X)=$ determined by the project Secondary work force $(Y)=1.25 X$ Total work force $(Z)=X+Y=2.25 X$ Number of households $(H)=0.67 Z=1.5 X$

Total population $(P)=3.30 \mathrm{H}=2.20 \mathrm{Z}=4.95 \mathrm{X}$

Limited efforts have also been made by Stenehjem and Metzger (1976) and by others to develop standardized multipliers with which to estimate the increases in various kinds of public services necessitated by a given amount of population growth. For instance, the following figures have been used in several recent impact forecasts:

Elementary students per household $=0.5$

Elementary school space requirements per child $=$ $90 \mathrm{sq}$. ft.

Hosp1tal beds per 1,000 pupulation $=2.1$

Primary-care physicians per 1,000 population $=0.8$

Police officer's per 1,000 population $=2.0$

Park land per 1,000 population $=1$ acre 
A distinction must be made, however, between multipliers that indicate what wil1 happen under a given set of future conditions, and those that indicate what should happen. Whereas demographic and economic multipliers generally give fairly objective estimates of expected future conditions, public-service multipliers often contain explicit or implicit assumptions of minimally acceptable or desired standards. For example, multipliers for number of police officers, primary care physicians, acres of park land, or square feet of elementary school space per capita do not represent results of project-induced population growth. Instead, they typically indicate additional services that must be provided by the affected community to maintain its current (or some minimal) levels of service. In contrast, multipliers for the creation of secondary jobs or the property tax base represent direct outcomes of such population growth, and do not involve any value decisions concerning desired community goals.

Quite obviously, a great deal more work remains to be done in developing these public service multipliers. Moreover, no multipliers are presently available for any community structure or social well-being factors. In addition, before nationally based multipliers are applied to any local area they must be checked against recent historical conditions in that area and modified to take account of any unique local discrepancies from the national standards.

\section{System Models}

Multivariate forecasting, in contrast to univariate forecasting, considers a number of related variables or indicators simultaneously, treating them as an interrelated system. To perform this kind of dynamic system analysis, it is necessary to construct a system model containing the total set of variables and relationships being examined. Each variable in the model must be quantified, and each relationship between variables expressed as a regression coefficient (which specifies the direction and amount of change in a dependent variable that will be produced by a unit change in a related predictor variable, net of the causal effects of all other related predictor variables). As sophisticated system models of 
various social processes are designed, quantified, and analyzed with computers, it will become possible to predict with relative accuracy all of the changes likely to result from a specified alteration in any one part of that system. Although such dynamic system analysis can never perfectly predict the future--since it cannot take into account unforeseen events that may change the system in unexpected ways--it nevertheless can greatly improve our ability to forecast social changes that may be produced by a proposed innovation.

\section{Flow Charts}

An initial step in constructing dynamic system models for multivariate forecasting is to develop flow charts that depict probable causal relationships among all relevant variables. Because the relationships shown in these charts are derived primarily from theory rather than research, they are only hypotheses that must eventually be tested through empirical research. In addition, this lack of empirical data also prohibits assigning quantitative coefficients to any of the relationships, although the direction of presumed causation can usually be inferred from the underlying theory.

The ten flow charts depicted in Appendix B were designed to schematically portray the sets of probable causal relationships comprising each of the five impact categories in the General Social Impact Assessment and Management Model shown in Figure 2--demographic, economic, community structure, public services, and social well-being--both without and with a proposed development project. For each of the five sectors, the first flow chart depicts conditions without the proposed project, while the second fllow chart shows conditions with the project.

The principal purposes of these flow charts are to 1) portray the numerous ways in which a development project can affect the social and economic conditions of a community, either directly or indirectly; 2) depict the most probable predictor variables and causal relationships for each of the 50 social indicators in our model; and 3) provide hypotheses for further research on causal relationships among all these community characteristics. 
Since these are only initial flow charts rather than finished system models, all relationships and causal effects in the charts should be viewed merely as hypotheses to be tested through empirical research. No regression coefficients are included for any of these relationships, since, those must also be determined through impact research. For simplicity, the charts are all recursive, without any two-way causal flows or feedback loops, although in reality these effects undoubtedly occur continually. A further simplifying assumption is that all effects among variables are additive in nature, so that no consideration is given to possible interaction among variables.

If it were possible to compute accurately all the "expected" and "predicted" forecasts contained in these flow charts, they would provide a quantitative basis for determining what changes would probably occur in a community if a proposed project were adopted. It is important to remember, however, that not all of these forecasted changes will necessarily be viewed as significant impacts by the residents of the affected community. Assessing which forecasted effects of a project would constitute significant social impacts is an evaluative process that uses these flow charts but goes beyond them in assigning value judgments to the quantitative forecasts.

Even in their present form, however, these flow charts should prove useful to social impact analysts, local governmental officials and planners, local community residents and leaders, and social scientists.

For analysts preparing social impact assessments, the flow charts are guides to relevant social indicators and their presumed interrelationships. At present, each impact assessment requires an in-depth empirical case study of the affected community on which to base its forecasts. If all of the relationships in these charts can eventually be quantified, however, the assessment process will be considerably simplified, requiring new data only on the current community conditions and the characteristics of the proposed project. Standarized regression coefficients would then be applied to these baseline conditions to obtain all needed future forecasts through systems analysis. 
Two particularly crucial aspects of this systems approach to forecasting are that it 1) places all the component variables in a meaningfui context, rather than treating them as isolated indicators, which hopefully will alert social impact analysts to the need for a broad range of relevant predictor variables; and 2) allows the analyst to forecast future conditions without the project as well as with it, which permits more accurate comparisons than the customary technique of comparing future conditions with the project to currently existing conditions. (The latter procedure ignores the continuous process of community change through time, and is likely to overstate the magnitude of project-generated changes.) Finally, these flow charts can also help the analyst identify a wide range of indirect and less obvious effects that a project may have on a community, thus permitting a more complete analysis of the total costs and benefits of the proposed project.

After these flow charts have been constructed for a specific community, they should be useful to local governmental officials and planners. For example, forecasts of expected demographic changes in the age structure, sex ratio, ethnicity, and educational level of a community would permit advance planning and program development to assimilate newcomers into the community. Similarly, these charts could also provide local officials with detailed information on future demands for public services and facilities of all kinds.

Community and organizational leaders should also find the flow charts useful in evaluating the desirability of a proposed project. Comparisons of the current, expected, and predicted profiles of the community should suggest a range of meaningful alternative futures that are potentially available to the community. Special interest groups would then be able to address whichever aspects of these potential futures were of concern to them, from increases in female labor force participation to decreasing requirements for police officers.

For social scientists, finally, the flow charts present a series of hypotheses for further empirical research. If a number of social impact 
studies would use the methodology suggested here and investigate the hypothesized relationships comprising these charts, the results would provide empirical grounds for attaching regression coefficients to these relationships that would specify their direction and strength. Longterm follow-up studies of communities that have experienced developmental projects are also needed to determine the accuracy of the prediction procedures and to identify necessary alterations in the methodology. As this research effort progresses through time, the flow charts may be transformed into fully developed system models depicting general processes of community change.

\section{ASSESSING POTENTIAL SOCIAL IMPACTS}

Many of the changes produced in a community by a development project or other innovation are so small in scope or trivial in nature that there is no reason to label them as social impacts. The purpose of the fourth stage of the social impact process, therefore, is to determine which of the expected innovation-related changes will probably have significant enough consequences to be considered serious social impacts.

Who makes these decisions? The social analyst performing the impact assessment could do this, an independent set of judges could do it, local public officials or community leaders could do it, or a sample of the community residents could do it. In practice, these decisions have commonly been made by the analyst with little or no input from others, which can be a source of serious bias. Preferably, the greater the number and diversity of people involved in this decislon-making process, the more likely they are to be relatively unbiased and balanced in nature. Each person's judgment of what constitutes a serious social impact for the community will reflect his or her social values, but with a wide range of values represented in this process, no single perspective should dominate the final judgements.

Regardless of how these assessment decisions are made, they will be influenced by at least four different considerations: 
- The importance of that factor to the quality of social life in the community, as defined by the prevailing values and judged by the individual making the assessment.

- The present or expected adequacy of that factor without the innovation, as determined by the actual discrepancy between existing or anticipated conditions and the commonly accepted ideal goal for that factor.

- The assessor's present or expected satisfaction with that factor without the innovation, as determined by his or her evaluation of the seriousness of the discrepancy between existing or anticipated conditions and his or her personal ideal for that factor.

- The observed or predicted nature and magnitude of change occurring in that factor as a result of the innovation.

To provide a factual basis for these assessment decisions, each of the predicted changes associated with the proposed innovation can be described (qualitatively if not quantitatively) in terms of several dimensions, such as:

- Probability: How likely is the change to occur?

- Primacy: Will the change be a relatively direct or more indirect consequence of the proposed action?

- Onset: Will the change occur relatively immediately or only after some delay?

- Duration: Will the change be temporary or permanent in length?

- Magnitude: How large or extensive will the change be?

- Distribution: What caleyuries ur groups of people will be most affected by the change?

- Scope: Will the change extend beyond the community to affect other communities, the state, or the region? 
On the basis of such information about the changes likely to result from the proposed action, the people participating in this evaluative process would then be asked to decide which of the projected changes would constitute significant social impacts. Total consensus should not be expected in this process, so that some criteria--perhaps majority rule-must be established for selecting the final list of significant impacts. Presumably, however, this final list of predicted social impacts will represent the most likely and serious effects on the community of the proposed innovation.

Once the significant impacts have been identified, their likely consequences for the people involved must be examined. What categories of people, economic sectors, neighborhoods, organizations, social institutions, etc., will be most directly and severely affected by each social impact? Will these effects be beneficial or harmful to the recipients? Will there be severe inequities in the distribution of the impacts on various recipients? How serious will these effects be viewed objectively? How serious will they be in the eyes of the recipients? This analysis will provide the information necessary for designing the impact management and amelforative strategies discussed in the next section.

Moreover, since many of these predicted social impacts may influence one another, the final analysis must view the total set of predicted impacts as an interrelated system. This means that the overall evaluation must involve a series of tradeoff judgments--either by public policy makers or by the people who would be directly affected by the impacts. For example, suppose the proposed project would reduce the unemployment rate in the region from $10 \%$ to $2 \%$, but would also necessitate raising property taxes by $50 \%$ to pay for additional schools, roads, utilities, and other facilities. Which is more beneficial or desirable: reducing unemployment or preventing a tax increase? Policy makers might render a decision on this issue, but many people would argue that final answers to these tradeoff questions must come from the people who will be most directly and significantly affected by them, on the basis of their own value systems. 
None of the factual knowledge generated through our proposed methodology will provide a final answer to the ultimate valuative question that policy makers must eventually face: Will this proposed innovation contribute to or detract from the quality of social life? When making this basic valuative decision, wise policy makers--either public officials or the general public--will take into account the nature, amount, and rate of social and economic changes that will likely result if the innovation is implemented, as well as the overall configuration of social conditions that will probably exist after these changes have occurred. With this information in hand, they can then evaluate the overall social desirability of the innovation and decide whether or not to adopt it. The role of our social impact methodology in this process is to enrich the knowledge base on which the final policy decision rests. An adequate knowledge base does not ensure wise decisions, but without it all decisions are 'capricious. 
THIS PAGE

\section{WAS INTENTIONALLY \\ LEFT BLANK}




\section{I. SOCIAL IMPACT MANAGEMENT}

\section{THE IMPACT MANAGEMENT PROCESS}

Impact management refers to efforts taken by both the public and private sectors to prevent, guide, or remedy the significant social and economic changes associated with energy or other development-related projects. This discussion focuses primarily on energy and resource developments located near and affecting small towns and rural areas, since local governments in these settings often possess few capabilities for coping with social and economic impacts.

Impact management is a topic of growing concern among researchers, planners, and decision makers and the state of the art has expanded rapidly since the early 1970s. A number of recent studies have examined ways in which communities can best cope with the social and economic impacts they experience (Gilmore and Duff, 1974; Twomey, 1974; Federation of Rocky Mountain States, 1975; Cox, et al., 1976; Howard, Needles, Tammen, and Bergendoff, 1976; Rapp, 1976). Several other studies provide guidelines and information on resources that can be used by local government for impact management (Briscoe, et a7., 1974; Federal Energy Administration, 1976b; Reiff, 1976; Williams, 1976).

Most of the efforts to date, however, have produced only handbooks and guidelines discussing planning and fiscal tools and programs that can be used to manage impacts. Absent from most of these writings has been any kind of general framework for impact management that identifies the key elements needed to plan successfully for the expanding needs of the affected community.

Our objectives here, consequently, are to provide 1) an overview of the social impact management process, and 2) a concise but comprehensive set of guidelines for state and local planners in carrying out this process. More specifically, what are the key components of impact management, and what factors determine the capability of local governments to devise and carry out impact management actions? 
COMPONENTS OF THE IMPACT MANAGEMENT PROCESS

The major components of the impact management process, as given in Figure 2 ( $p .5)$ and discussed briefly in the Introduction, are the community's existing functional capabilities, existing planning and management capabilities, goals, impact amelioration requirements, planning and management needs, potential planning and management resources, and recommended planning and management strategies. Each of these components is discussed in more detail in the following paragraphs.

Existing Functional Capabilities

To determine accurately a community's ability to manage expected or potential social impacts, two sets of baseline information are necessary. One of these is data on the existing capabilities of local governments to provide public services such as sewer and water, road maintenance, schools, etc. It is particularly important to determine the "carrying capacity" of each of the services or functions the local government is expected to provide. If the service is presently operating close to or at full capacity, expansion may be required if the population increases rapidly.

Existing Planning And Management Capabilities

The second kind of baseline information necessary to assess a community's ability to manage impacts is data on its existing planning and management capabilities. The extent of these current capabilities will directly affect the community's needs for additional planning and management programs to cope with the anticipated social impacts. Existing capabilities include the presence of professional or experienced planning staff, the amount of money available for planning in the community, and a demonstrated willingness on the part of the community to take part in a planning process.

Community Goals

A community's current and future goals will also directly affect its responses to anticipated social impacts. Such goals as the amount and direction of desired growth and the quality and style of life valued by a community are critical parameters for impact management decisions. If a 
community does not want permanent growth, for example, then an overload on some existing public service for a short period (such as during the construction of a project) might be a wiser planning decision than expanding services to meet the demands of a large population that the community does not want. Impact Amelioration Requirements

These requirements -- which are determined by the predicted social impacts, the community's existing functional capabilities, and its goals -specify the problems the community will likely face in coping with the expected impacts. What additional mitigation or amelioration measures are needed to effectively manage those impacts will then become apparent. These impact amelioration requirements might include expanded employment services, property reevaluation, additional housing, more roads and schools, expanded recreational facilities, or new community organizations. Detailed specification of these probable amelioration requirements for a community is the most crucial step in the total impact management process.

Planning and Management ileeds

Once its impact amelioration requirements have been determined, a community can then assess the ability of its planning and management capabilities to meet these requirements. For example, will additional professional staff be required to design or administer programs to alleviate social problems or service overloads? Do community officials have sufficient expertise to determine how and where additional revenues may be obtained, and how and where technical assistance may be available? A community must evaluate carefully its ability to plan for the expected social impacts identified and whatever additional planning and management needs it will experience as it seeks to cope with those impacts.

\section{Potential Planning and Management Resources}

If the community requires additional financial or technical resources to meet its planning and management needs, potential sources for these resources must be identified. This is accomplished through a careful examination of all existing and potential programs available at the state and 
federal levels, as well as whatever technical and financial contributions may be obtained from the project developer. The applicability of these programs and their contribution to the local community must also be carefully evaluated. Recommended Planning and Management Strategies

A11 the information gathered in the preceding steps of the impact management process feeds into this final component. Based on 1) an evaluation of the need for impact management or amelioration programs, 2) the capabilities of the local government to meet these needs, and 3) the potential availability of additional planning and management resources, a community can develop a planning program to manage any expected social impacts. This program should include recommendations for the specific strategies to be used to manage the impacts, as well as provide overall directions for future community development as it copes with a variety of social impacts.

\section{GUIDELINES FOR SOCIAL IMPACT MAIIAGEMENT}

The key elements necessary for successful impact management, as described in the preceding section, are described below. The discussion is divided into two parts: 1) basic guidelines essential to the effective management of community social and economic impacts; and 2) interrelations between the planning and decision-making processes.

We have identified seven guidelines that can be used by local officials and planners to manage the social and economic impacts associated with energy and resource developments. These guidelines have been synthesized from discussion with state and local officials involved with energy development and with social impact assessment and management. They are summarized in Table 1.

Underlying these guidelines for impact management are two critical points. First, to implement the guidelines, local governments may have to expand their planning and management capabilities. Although the first three guidelines pertain to ongoing planning efforts in most communities, the last four guidelines are project-oriented and may require that a government hire additional. personnel or contract outside consultants to perform needed professional services. 


\section{TABLE 1. Guidelines for Social and Economic Impact Management}

1. INVOLVE THE PUBLIC IN THE COMMUNITY POLITICAL PROCESS: If impact management efforts are to accurately reflect the goals and needs of a community, citizens must take part in local political decision-making processes. A community run by a handful of people or one interest group will reflect only the desires of that small fraction of the community. The public must be convinced that impacts will occur but can be minimized or ameliorated through a planning process that involves citizens in identifying both problems and their solutions:

2. DEVELOP AND IMPLEMENT A COMPREHENSIVE COMMUNITY PLANNING PROCESS: Comprehensive planning is vital for coordinated impact management. A comprehensive planning process can assure that all important social and economic changes are examined in a systematic fashion. This planning should be an integral part of the overall decision-making process.

3. DEVELOP AND MAINTAIN AN ACCURATE AND CURRENT INFORMATION BASE: Planning and preparing for social and economic impacts requires accurate and timely information. Local officials must be aware of potential data sources and be willing and prepared to collect whatever data will be required to understand the effect of a proposed project on the community and to meet the resulting community needs. This particularly includes changes that will affect public service and budget decisions.

4. INITIATE A COOPERATIVE WORKING RELATIONSHIP WITH THE DEVELOPER: LOCal governments should try to develop a cooperative working relattonship with the developer so that they have access to necessary information. This relationship will also increase the likelihood that the developer and community will cooperate in developing planning strategies. A regional government or council of governments (COG) may be in the best position to facilitate an information flow from developer to

- affected community.

5. IDENTIFY IMPACTS EARLY: Local and regional government must have sufficient time to plan for anticipated social and economic impacts. This includes time for any needed new applications, time to wait for other governments' budgetary and funding cycles, and time for the construction of any needed new community facilities. This activity should be performed early to ensure that the impact management process will be integrated into the overall community planning and decisionmaking processes. In fact, mitigation measures for social and economic impacts often require more lead time than mitigation measures for environmental impacis. Thus it is crucial that the identification process begin early.

6. FIND AND OBTAI iN ADEQUATE RESOURCES: An important aspect of planning for community impacts is knowledge of the resources (including local legal powers) that exist at the local level and how to obtain necessary additional financial resources or technical aid. Local governineint should seek this information as soon as it is aware that potential impacts may occur.

7. ESTABLISH INTER- AND INTRAGOVERINMENTAL COORDINATION AND COMMUINICATION: It is visal that regular communication occur among all affected agencies so that all can contribute suggestions arid possible solutions to problems as they arise. Regional governments may be the most appropriate vehicle for assuring that this communication takes place. 
Second, local governments must be able to cope with the uncertainty that accompanies the early stages of most large-scale developments. To meet the needs that will arise when rapid growth occurs, the government must develop plans, obtain funds, and possibly build facilities or develop services before the project begins. And because of the long lead time required for programs that depend on federal or state funding, local governments must anticipate their requirements before the nature and scope of these needs are at all definite. To deal with such uncertainty, communities must often develop several alternative plans, identify alternative sources of financing, and prioritize anticipated social impacts.

\section{Involve The Public In The Community Political Process}

In many small communities, particularly. in rural areas, the people desire little governmental control over or interference with their daily lives. Hence, local government provides few services or facilities. This system works well as long as few demands are placed on the public sector. In such situations, the political system often is dominated by small groups of people or special interest groups. Most other members of the community do not feel the need to participate actively in the political process since few decisions are made that greatly affect their lives. However, when a community is faced with a large-scale energy development project and an influx of people with different values or needs, it must make numerous critical decisions regarding all aspects of its future growth and direction. Under these conditions, it becomes imperative that more citizens be involved in the community decision-making process. Without widespread public awareness and involvement, crucial decisions concerning the entire community will likely. reflect the interests of only a small minority of the population. If citizens are not already informed about and involved in the local political process, local government should take immediate steps to encourage such participation so that the decision-making process will consider the concerns of the total community.

Must Be Convinced That Impacts Will Occur. It is not uncommon to find some local officials and residents who are so enthusiastic about a proposed project that they refuse to acknowledge or discuss potential social and economic impacts. Individuals and groups who desire growth 
may want to do nothing to discourage project development in their area, and may feel that recognition of potential impacts might be interpreted as a negative response to the project. In addition, they may be convinced that the benefits outweigh the negative effects. However, to prepare most effectively for the changes that will take place (even though they may be welcome changes), local officials and citizens must recognize that there will be impacts with which they must deal. Planned change can be used to effect improvements and to reduce some of the costs of growth for a community.

Must Support The Planning Process. Once the community recognizes and accepts the fact that social and economic changes will result from the project, officials and residents must be willing to plan for these changes. Such planning should include budget analyses to re-examine priorities, land use planning to better control the direction of growth, and comprehensive planning to systematically provide community services and facilities and to coordinate various elements of the public sector. Citizens and elected officials should be aware that while change may be used to improve local services and facilities, such improvements depend on foresighted planning. Elected officials must be willing to participate in planning efforts and to provide the appropriate mechanisms for implementing suggested planning approaches and strategies. In addition, community residents should actively support or even initiate efforts to plan early for the anticipated impacts.

Must Develop And Use Communication System In The Community. A communication network must be established to facilitate the availability and exchange of information among citizens in communities and the region affected by rapid growth. In most communities a weekly newspaper can be used by the developer and by local, regional, and state agencies to inform the public about the nature and progress of the development and the related community growth impacts. The public also may use this vehicle to express their opinions and concerns about the development. If there is no local newspaper or radio/TV station, local officials and planners must employ other techniques--such as formal and informal meetings and discussions, displays in public places, and brochures--to inform the public and to allow for public expression of concerns arid suggestions. 


\section{Develop And Implement A Comprehensive Community Planning Process}

To use their resources most effectively and to develop appropriate strategies for coping with identified social and economic impacts, affected communities must have comprehensive planning processes. This process should be ongoing and flexible enough to deal with whatever changes the community experiences. Comprehensive planning helps to guarantee the effective management of impacts. This process will examine all potentially affected or changing aspects of community life, from health care and mental health to the provision of police and fire services and water and sewer facilities. Moreover, all of these separate elements must be integrated into a comprehensive plan that treats the total community as a dynamic interrelated system.

Relate Planning To Land Use. Community planners and planning commissions are usually most interested in land use. When communities are faced with rapid growth, however, planners and local officials must broaden their concern to include many. other planning issues. By relating these other concerns (e.g., projection of project-related revenues and expenditures, the assessment of social and economic impacts, etc.) to land use, decision makers and planning commissions will understand better the need for a comprehensive approach to community planning.

Relate Planning To Decision-Making Process. Planning provides a framework for informed decision-making. To be useful, planning must relate to and influence critical local decisions when they are being made. Thus, elected officials and other public servants must support and understand the planning process and work toward its full implementation. This includes county sheriffs and city engineers as well as county commissioners and city council representatives. One of the most significant decision-making points where the comprehensive planning process should be used for guidance is the budget plan for the city and county.

3. Develop And Maintain An Accurate And Current Information Base

A local government facing significant social and economic changes requires two types of information. One is data on existing characteristics, 
conditions, and trends in the community and the county. The other is projected data on future characteristics, conditions, and trends in that area.

An accurate information base is essential if planning efforts are to effectively identify and implement appropriate measures to cope with social and economic impacts. Thus a local community should begin to establish the data base needed to plan for and manage anticipated social and economic impacts at the time a development project is first announced.

What To Include In The Information Base. The categories of information to include in such a data base are 1isted in Table 2. This information provides a baseline description of the community before the impacts occur.

Where To Get The Information. Local officials can use an impending development project as an appropriate time to collect or update various types of useful data for their area. Such data collection requires much personal contact with local clerks and other government officials, as well as a certain amount of data aggregation and computation. Census data also can be difficult to work with if they are more than a few years old. Most states generate some data on their counties and local communities, much of. which may be useful to a local area establishing a data base. The data source of most use to local officials appears, however, to be various local governmental offices.

4. Initiate a Cooperative Working Relationship with the Developer

The utility or agency initiating a development project is potentially the most accurate source of information about the nature, scope, and timing of the project. It is important that the developer provide the community with accurate and timely information on the construction schedule, size of work force, material transportation needs, tax information, and other relevant information about the project. It is also critical that the developer and the local government establish and maintain a close working relationship throughout the construction and operation of the project, since all parties generate information that is essential to the others' efforts. 


\title{
TABLE 2. Baseline Social and Economic Data(a)
}

\author{
Population Characteristics \\ Population size by sex, age, race \\ Degree of urbanization \\ Family size \\ Education attainment \\ Labor force skills required \\ Economic Characteristics \\ Gross economic income \\ Economic base/diversity \\ Employment/unemployment rates \\ Job availability and diversity \\ Job training availability \\ Family and personal income \\ Cost of living \\ Retail facilities \\ Tax base (incluae propercy, ousiness and \\ occupation, utility and sales \\ Community Structure \\ Assuciations \\ Mass media \\ Housing \\ Meanl market value \\ Vacancy rate \\ Housing distribution type \\ Public housing \\ Existence of federal or state assistance-- \\ type and amount \\ Rental scale \\ Social Well-Being \\ Crime and delinquency \\ violent crimes/1000 population \\ property crimes/1000 population \\ ar res ls for utsorderly conduct, drunkenness \\ Mental health \\ number of clinics and contacts by type \\ Emotional difficulties \\ number of incidents truancy/student \\ population \\ number of incidents vandal is $\mathrm{m} / \mathrm{student}$ \\ Poverty \\ proportion of families below poverty line \\ proportion of families receiving public \\ welfare \\ Planning and Administrative Capabilities \\ Existence of planning bodies (local and \\ regional) by type \\ Number of planners/iưu popliarion \\ Existence of federal or state assistance \\ by type and amount \\ Total amount of money allocated for planning \\ Public Services \\ Government \\ numher nf emplnyeps/arlu!iniștratour's \\ total local revenues \\ total local expenditures/capita
}

(a) To be most useful, it is important to collect these data at several points in time in order to monitor the changes resulting from project development. (Possible data collection periods include one point before project iniception and several puints Juiling constiuction. It will be necessary to collect some data monthly or quarterly once construction begins.) 
While the project developer is likely to make contact with affected communities to establish good public relations, frequently it is still up to the local government to ask for specific information about the characteristics of the project that are needed to anticipate and plan for community impacts. Therefore, the affected governments must be prepared to take the lead in establishing a working relationship with the developer. In some situations a regional council of governments can play a useful coordinating role, acting as a mediator for all affected local governments.

The Exchange of Information. It is desirable that the developer and the community share information and plan for the project together, as far as possible. Local officials will need various kinds of information from the developer, such as project construction schedules and labor force requirements. The developer, in turn, will need to know about local zoning ordinances, tax rates, and other factors that will affect the project. The existence of an ongoing working relationship will facilitate the exchange of such information.

State and Local Powers. State and local governments possess certain powers that can be used to assure that the developer takes social and economic factors into consideration and complies with applicable restrictions and requirements. Local governments should be aware of the nature and extent of leverage they can exert through techniques such as local zoning and comprehensive planning powers, as well as participation in relevant state or federal decision-making. In the state of Washington, for example, a representative of the affected local government is a temporary member of the state Energy Facility Site Evaluation Council during the consideration of each facility. As a condition of certification, the Council may require the developer to provide information and in some cases compensation for specific impacts to local governments.

The Developer's Role. The developer's role in managing community impacts is in a state of evolution. It is therefore difficult to make generalizations about the extent to which a developer will consider local values and how much responsibility it will assume for providing assistance 
for social impacts generated by its project. In the past, developers have often felt that community impacts were not their responsibility. This situation is beginning to change, however, and many developers are taking some initiative in helping communities to manage impacts. On the other hand, more local governments are also demanding that developers assume responsibility for impacts they generate. The current trend is for the developer to make early contact with affected communities and to negotiate the level and types of assistance it is prepared to provide to the community. The following brief examples illustrate the wide range of involvement that energy developers currently have in community impact management:

- In Skagit County, Washington, the county commissionners refused to grant the original rezone that Puget Sound. Power and Light Company requested in order to construct two nuclear power reactors. The county used this power as a leverage to negotiate with the utility for prepayment of taxes to help finance necessary expansion of law enforcement and educational facilities and programs. The result was a rezone contract--a formal agreement between the county and the utility regarding the utility's responsibility in mitigating these impacts caused by the project.

- Seattle City Light, as owner and operator of several hydroelectric facilities in washington state, has taken the initiative to mainlain "good neighbor" relationships with the communities it owns or affects with its facilities. It has taken a more informal approach to impact mitigation assistance, heiping to locate and buy fire equipment for one community, assisting another community to acquire land and develop a park, and loaning an antique train engine for use as a tourist attraction in a third community.

- The Washington Public Power Supply System (WPPSS), which is building two nuclear reactors near Hanford, Washington, has initiated efforts to help the community identify and mitigate impacts related to their facilities. However, there is disagreement between the utility and local government about the level of assistance that the utility should 
be required to provide. Here, formal negotiation and agreements are underway as in Skagit, but initiated by the utility as well as the local government.

- Finally, in the case of the Sundesert nuclear power plant in California, the San Diego Gas and Electric Company has taken the initiative in devising a very comprehensive approach to identifying and managing local impacts and in monitoring the effectiveness of impact mitigation efforts. Planners with expertise in impact management have been employed in a consulting capacity by the utility. They have integrated the affected local communities into the planning process and are working with the communities to develop impact management strategies before the impacts will occur.

As can be seen from these illustrations, different approaches have been taken by developers to meet their perceived responsibilities in managing community impacts. Since this role is directly affected by state laws and regulations, it is important for local governments to understand the legal requirements in their state before they seek specific assistance or agreements from the developer.

\section{Identify Impacts Eàrly}

Local governments affected by energy development projects are particularly in need of early and accurate information regarding the project so that they can initiate planning to meet the resulting needs. They also must begin early to set up a communication process with all affected parties and interested observers, including appropriate federal and state officials, as well-as the project developer.

Planning Coordination. It is essential that small and/or rural local governments work in coordination with other governmental agencies, including regional councils of government, throughout the duration of the project. The earlier all affected governments are informed of the project, the easier it is for them to establish such coordination. Serious problems also can be caused by lack of appropriate notification and identification of impacts as they occur. This situation causes local governments to lose critical time needed for their own planning and budgelary processes, and for their 
funding applications to other governmental agencies. The regional government can, in some situations, facilitate this coordination and communication by acting as a clearing house for information.

Coordinate with Other Governments' Budget Cycles. State and federal governmental levels often do not have the same budget cycle as a local government and thus may require extensive lead time for any new funding request. In addition, state and federal agencies may be constrained in what and who they may fund through priorities set each year by state and federal policy makers.

6. Find and Obtain Adequate Resources

Planning for and managing the social and economic impacts associated with a large development project requires massive commitments of personnel time and can require additional financial resources. Many communities faced with a large project have little idea of how to plan for the changes and impacts such a project will bring. Lacking familiarity with the range of potential social and economic impacts, local officials are likely to have difficulty knowing beforehand what changes to expect and what resources to seek. This lack of knowledge (and sometimes appreciation) concerning both needs and sources of additional resources exacerbates the problem of coping with the impacts. Thus, by the time community officials recognize the problems and know what kinds of resources they need, it may be too late to obtain some forms of assistance that might have been available with earlier planning.

Adequate Staff Time. Most communities faced with the prospect of an influx of hundreds of construction workers and their families will spend large amounts of staff time assessing and planning for potential impacts. For many communities this additional staff time is not easily made available. Other programs must suffer while people are temporarily assigned to the impact study. One alternative to this procedure is for the community to obtain additional funding for this planning effort. Another more immediate solution is to solicit citizen volunteers to help with local data gathering efforts. Such volunteers can make significant contributions to the community, if they have professional staff support. 
Financial Resources. If it is obvious to local planners and decision makers that a community's existing financial and technical resources will not be adequate to cope with the predicted social and economic impacts, outside additional resources then must be sought. In some cases these resources may be needed only temporarily, until property taxes on a project begin coming into a community. In such cases,' the developer may prepay some property taxes to provide "front-end" money for needed new community facilities. In other cases, it may be necessary for a local government to seek additional monies from state and federal sources. Various state and federal programs are specifically designed to provide community impact assistance. In addition, the rapid growth may qualify local governments for additional state and federal monies under existing programs providing aid to communities, or for additional state and federal programs.

Most financial assistance is available through federal programs, while state assistance is usually limited to technical assistance. Several publications are available which describe the full range of potential sources of financial assistance to communities impact by energy developments. (Williams, 1976; FEA, 1976b; Rapp, 1976). Major sources of such assistance are several ongoing federal programs for which impacted communities may be eligible. These programs include impact assistance under the Coastal Zone Management Act; Economic Development Administration grants for community facilities; Department of Health, Education, and Welfare grants for family heal th centers and emergency medical services; and Housing and Urban Development community block grants.

Awareness of Community Limitations. Local officials should be aware of any limitations in their state regarding local generation of new revenue sources. Local officials must be thoroughly familiar with their bonding limitations and capacities. They also must have knowledge of all other capital projections in the community in addition to. whatever new facilities will be required by the project work force. They must be aware that bonding companies won't necessarily speculate with a community since large risks are involved in the construction of energy facilities. Finally, local officials must operate under the constraint that general obligation bonds depend on voter approval, which is not always easy to obtain. 
7. Establish Inter- and Intragovernmental Coordination and Communication with all Affected Agencies

Certain impacts of a development project may create severe problems for a community and are likely to raise complex and difficult questions concerning who will assume responsibility for the impacts, what are the best techniques for forecasting them, what are the most appropriate planning strategies for impacts, and what and where suitable sources of financial aid for the impacts can be found.

Make Numerous Contacts. The above questions become complex partly because their solutions involve many agencies at all levels of government. This makes it imperative that local governments in affected areas establish and maintain communications with other local and regional as well as state and federal agencies involved in local assistance. Without such contacts, local government is not likely to know about or take advantage of potential sources of technical and financial assistance, or may not be aware of its responsibilities in applying for such assistance. Most state and federal assistance is available only to those communities that apply for funds, with the exception of some revenue-sharing funds. Presumably, therefore, asșistance goes to areas where it is wanted and needed. However, this arrangement also puts the primary burden on local governments, which may not know about potential sources of aid or application procedures. Communication with reilevant agencies will help local governments to best use all potential resources. A regional planning organization, if there is one, is a logical clearinghouse for such information, and can facilitate communication among local governments and between local, state, and federal agencies.

Uiscuss Mutual Problems. It is quite important in large-scale development situations that the various affected local and regional agencies talk with each other regarding mutual problems and potential solutions. Any agency rivalries which impede an efficient problem-solving operation need to be put aside when planning for a project that can substantially affect the entire community. Well-coordinated local and regional governments, with representatives who confer regularly with other local and regional officials and appropriate state and federal officials, are a crucial requirement for adequately managing 
community impacts. Such organization is important. when a local government is requesting funds from new sources such as federal agencies, and when it is negotiating with the project developer. It also strengthens the government's position when bargaining for policies and actions that can directly benefit the community.

Summary

All of the guidelines presented here have a temporal factor. If the timing is not right, it may be difficult to initiate certain impact management steps. It takes time to formulate plans, find solutions, and obtain money to build facilities or implement programs. Local government therefore must estimate timing needs and plan their actions accordingly.

Early contact with the project developer is essential for accurate identification of potential impacts, which in turn is vital for adequate planning. Effective planning also requires substantial community involvement and commitment, knowledge of all available resources and all government agencies involved in the impact planning process, and wel1-prepared financial planning. Thus, one can quickly see that all the impact management guidelines interact with each other, and that these guidelines must be initiated sufficiently prior to the beginning of the project if the local community is to plan effectively for and manage the resulting social and economic impacts.

\section{RELATIONSHIPS BETWEEN PLANNING AND COMMUNITY DECISION MAKING}

The preceding discussion of impact management guidelines gave major emphasis to comprehensive planning for such topics as land use, social services, housing, transportation, health services, recreation, public safety, and public services. In this final section, we focus on the integration of planning and management into the local governmental decision-making process.

Planning is not a separate activity based solely on an objective evaluation of all possible alternative solutions to a problem. Rather, it occurs within the governmental decision-making process, and therefore must take into consideration differing interests and values in the community. Impact planning and management must be a process of negotiation and compromise. 
Role of Local Planning

At the local level, planning provides a comprehensive framework for considering future needs and for integrating various elements of the physical and social infrastructure. It enables community officials to better decide how and where development should take place, and how local services should be provided so that they are consistent with local values and preferred lifestyles. With such a framework, local government is better able to identify its existing capabilities for absorbing rapid growth impacts and to determine how policies, programs, or facilities can be changed or expanded to cope with new or increased demands.

In many small communities there is no formal planning function in the local (municipal or county) governmental structure. At most, there is an elected local council or county commission which comprises the legislative decision-making body. The council or commission is the decision body for al1 local issues including development-related requests in the jurisdiction. Sometimes rural communities may have a planning commission which serves as a hearing body for zoning and land use matters.

Under conditions of slow or no growth in small communities, the planning functions that do exist may be performed by local officials or lay commissions. However, in the case of impending rapid development, such as energy facility development, the need for professional planning capabilities is critical. Planners can collect and anaiyze information about the physical and social infrastructure characteristics of the community and help develop and implement programs and policies within the local governmental structure. Thus, planners are technical resource people who provide local decision makers with a comprehensive, analytical perspective on local needs and options for managing impacts within a systematic and long-range planning framework.

At the same time, elected officials must examine and weigh information and priorities of other interests and groups in the community in its decisionmaking process. Hence recommendations by planners may be modified or changed to reflect other political factors. In short, the political process of bargaining among groups with different goals and interests is an integral part of formulating and implementing policies and programs to mitigate impacts. 
Regional Planning

While the role of regional planning bodies varies significantly among and even within states, they potentially have an important coordinating role between local governments and state and federal agencies. Like local governmental entities, regional planning bodies derive their powers from the state or from a group of local governments that voluntarily give some of their planning powers to a regional body. Often they have only advisory roles, but even this can provide a regional perspective and comprehensive planning capabilities. that are important to impact management.efforts. An additional important contribution of regional planning organizations is the compilation of current data on the region for all aspects of planning; including physical characteristics, social service capabilities, public services, etc.

\section{State Planning}

Most states have a planning or community development agency that develops and administers state policies and programs to aid communities throughout the state. Although few states have developed state land use plans, most states do support local planning and impact management. In addition, state planning directly influences local governments if state-owned lands and facilities are involved.

A state planning agency is a good source of information for local governments, particularly regarding revenue sources and formulas and fiscal planning. Also, state planning agencies may assist local governments in identifying and applying for federal financial assistance.

Summary

The intention of this brief discussion has been to create a better appreciation of how impact planning and management fits into the overall community decision-making process. This decision-making process is the key arena for managing community impacts. While state and federal agencies may provide financial and technical support, it is essentially up to local governments to initiate policies and programs with which to manage social impacts. And most planning for and management of impacts must occur on the local level. One must remember, however, that the purpose of planning is to 
promote informed decision making. Hence it must be an integral part of the decision-making process, not a separate activity. The planning efforts undertaken in a community should relate to the decisions that must be made, so that they remain relevant to local needs and problems.

\section{CONCLUSIONS}

In this discussion of social and economic impact management, we have laid out a set of guidelines to provide local planners and decision makers with an overall understanding and appreciation of several key actions, processes, and cápabilities which local governments must demonstrate if they are to respond quickly and effectively to large social and economic impacts. As one can see in examining these guidelines, the ability of local governments to cope with rapid growth impacts depends largely on three interrelated factors: 1) the timely availability and use of information within 2) a comprehensive planning framework which is 3) an integral part of the political process in which citizens are actively involved. State and federal levels of government are not likely to effectively manage social and economic impacts occurring in a local area. Rather, local governments, as representatives of local interests and values, must be the moving force in this whole process of determining what is an impact, whether it is beneficial or adverse, and what, if anything, needs to or will be done to prevent or respond to it.

Finally, it is important that the residents of the local area take an active interest and role in the local. decision-making process. If only a small segment of the community's residents are involved in this process, problems can arise when the community is faced with rapid growth. Additionally, good administrators are'needed to effectively deal with growth-related impacts and with the range of citizen concerns and values that will surface when citizens become involved in the decision-making process. The ability of these administrators--elected officials in small communities or professional staff in larger communities--is a principal factor determining a community's capability for managing social impacts. In short, competent and involved people make the impact management process work. 
Andrews, F. M. (1974) "Social Indicators of Perceived Life Quality Quality," Social Indicators Research, Vol. 1; p. 282.

Battelle Human Affairs Research Centers. (1975) "Identification and Management of Economic and Social Impacts of Nuclear Energy Centers: A Preliminary Analysis." Report to the U.S. Nuclear Regulatory Commission.

Bauer, Raymond A., ed. (1966) Social Indicators (Cambridge, Mass.: MIT Press).

Bloom, Mitchel F. (1975) "Deterministic Trend Cross-Impact Forecasting," Technological Forecasting and Social Change Vol. 8, pp. 35-74.

Booz, Allen and Hamilton, Inc, (1973) "The Quality of Life Concept: A Potential New Tool for Decision-Makers" (National Technical Information Service, PB-225 089).

(1974) "A Procedures Manual for Assessing the Socioeconomic Impact of the Construction and Operation of Coal Utilization Facilities in the 01d West Region" (Washington, D.C.: 01d West Regional Commission).

Briscoe, Maphis, Murray and Lamont, Inc: (1974) "Tax Lead Time Study: The Colorado 0il Shale Region" (Denver: Colorado Geological Survey).

Bureau of Reclamation and Institute of Applied Research. (1975) "Anticipated Effects of Major Coal Development on Public Services: Costs and Revenues in Six Selected Counties" (Denver: Northern Great Plains Resources Program).

Campbe11, Angus, Philip E. Converse, and Willard L. Rogers. (1976) The Quality of American Life (New York: Russel Sage Foundation).

Cox, Jack, Gerry Coan, Donald Krumm, Robert Goetz and L. 0. Houstoun, Jr. (1976) "Rapid Growth in Southwest Wyoming" (Washington, D. C.: U.S. Department of Agriculture and U.S. Department of Housing and Urban Development).

Curry, Martha, Jill Goodnight, Marjorie Greene, Donna Merwin and Randall Smith. (1977) "State and Local Planning Procedures Dealing with Social and Economic Impacts from Nuclear Power Plants" (Seattle, WA: Battelle Human Affairs Research Centers for the United States Nuclear Regulatory Commission). 
Department of Health, Education, and Welfare. (1969) Toward A Social Report (U.S. Government Printing Office).

Dornbusch, David M. and Company, Inc. (1976) Management of OCS-Related Industrial Development: A Guide for Alaskan Coastal Communities, prepared for the Alaska Department of Community and Regional Affairs, Division of Community Planning.

Dunning, C. Mark. (1974) "A Systemic Approach to Social Impact Assessment," in C. P. Wolf, ed., Social Impact Assessment (Environmental Design Research Association).

[dwards, R. G., A. B. Bruadersun, dild W. P. Hauser. (1976) "Social Economic and Environmental Impacts of Coal Gasification and Liquefaction Planls" (Leximytun: Instltute for Mining and Minerals Research, University of Kentucky).

Energy Policy Project of the Ford Foundation. (1974) A Time To Choose (Cambridge, Mass.: Ballinger Publishing Co.).

Federal Energy Administration. (1976a) "Summary of Proceedings, Workshops on Financial Aspects of Socioeconomic Impacts of Energy Resource Development," sponsored by Federal Energy Administration Office of Energy Resource Development, Dillon, Colorado, August 3-5.

- (1976b) "Federal Assistance Programs and Energy Development Impacted Municipalities" (Washington, D.C.: U.S. Federal Energy Administration).

Federation of Rocky Mountain States, Inc. (1975) Energy Development in the Rocky Mountain Region: Goals and Concerns (Denver: Federation of Rocky Mountain States).

Finsterbush et al. (1975) "A Methodology for Analyzing the Social Impacts Impacts of Public Policies" (The BDM Corporation).

Finsterbusch, Kurt, and C. P. Wolf, eds. (1977) The Methodology of Social Impact Assessment (Stroudsburg, PA.: Dowden, Hutchinson, and Ross, Inc.).

Fox, Karl A. (1974) Social Indicators and Social Theory: Elements of an Operational System (New York: John Wiley \& Sons).

Gilmore, John S.; and Mary K. Duff. (1975) Boomtown Growth Management: A Case Study of Rock Springs-Green River, Wyoming (Boulder, CO: Westview Press). 
Gilmore, J.S., Keith D. Moore, Diane Hammond, Dean Coddington. (1976) "Analysis of Financing Problems in Coal and 0il Shale Boom Towns" (Denver: Denver Research Institute, prepared for the Federal Energy Administration).

Gross, Bertran, ed. (1967) "Social Goals and Indicators for the American Society," Volumes I and II. "The Annals of the American Academy of Political and Social Science, May and September.

Howard, Needles, Tammen, and Bergendoff. (1976) "Temporary/Mobile Facilities for Impacted Communities" (Washington, D.C.: 01d West Regional Commission).

Jones, Bernie, and Charles Cortese. (1976) "Patterns of Boomtown Experiences: Implications for Future Work in the Field of Social Impact Assessment" paper presented at the annual meeting of the Society for the Study of Social Problems.

Land, Kenneth C., and Seymour Spilerman. (1975) Social Indicator Models (New York: Russel Sage Foundation).

Leistritz, F. Larry, and Steven H. Murdock. (1977) "Research Methodology Applicable to Community Adjustment to Public Land Use Alternatives," discussion paper at the Forum on the Economics of Public Land Use in the West, Reno, Nevada.

Lui, Ben-Chieh. (1975) Quality of Life Indicators in U.S. Metropolitan Areas, 1970: A Comprehensive Assessment (Kansas City, Mo.: Midwest Research Institute).

Martino; Joseph P. (1976) "Survey of Forecasting Methods" World Future Society Bulletin (November/December), pp. 3-10.

Micklin, Michael, ed. (1973) Population, Environment, and Social Organization: Current Issues in Human Ecology (Hinsdale, 111.: The Dryden Press).

Mountain West Research, Inc. (1975) "Construction Worker Profile: Final Report" (Washington, D.C.: 01d West Regional Commission).

Myhra, David. (1976) "Energy Development: Dealing with Social and Économic Impacts" Practicing Planner, Vol. 6, (September), pp. 12-22 and 46-47.

Northern Great. Plains Resources Program (NGPRP). (1975) "Effects of Coal Development in the Northern Great Plains: A Review of Major Issues and Consequences at Different Rates of Development (Denver: Northern Great Plains Resources Program). 
0lsen, Marvin E., and Donna J. Merwin. (1976) "Toward a Methodology for Conducting Social Impact Assessments Using Quality of Social Life Indicators" (Battelle Pacific Northwest Laboratories Report BNWL-2084, RAP-2). Reprinted in Kurt Finsterbusch and C. P. Wolf, eds., The Methodology of Social Impact. Assessment (Stroudsburg, PA: Dowden, Hutchinson, and Ross, Inc., 1977).

Perloff, Harvey S., ed. (1969) The Quality of the Urban Environment Baitimore: The Johns Hopkins University Press).

Rapp, Donald D. (1976) "Special Report to the Governors: Western Boom Towns: Part I. Amended: A Comparative Analys is of State Actions" (Denver: Western Governor's Regional Energy Policy Office).

Real Estate Research Corporation. (1975) "A Discussion of the Problems and Future Development in Three Communities Affected by Energy Development in the West: Supporting Documentation for Defining and Measuring Excess Cost Burden" (Washington, D.C.: Office of Minerals Policy Development, U.S. Department of the Interior).

Recht, J. Richard, and Priscilla A. Greene. (1977) "A Methodology for Assessing the Impact of Electric Generating Facilities on the Local Economy" paper presented at a symposium sponsored by the Atomic Industrial Forum and Edison Electrical Institute, St. Louis, Missouri.

Reiff, Isabel. (1976) Managing the Social and Economic Impacts of Energy Developments (Washington, D.C.: Energy Research and Development Administration). 1

Sheldon, Eleanor B., and Wilbert E. Moore. (1968) Indicators of Social Change (New York: Russell Sage Foundation).

Stenehjem, Erik J., and James E. Metzger. (1976) "A Framework for Projecting Employment and Population Changes Accompanying Energy Development, Phases I and II," Argonne National Laboratory, Chicago, Itlinois.

Twomey, James P., and Peter G. Kuh. (1974) "Governmental Programs, Resources and Regulatory Powers Available to Assist Localities During Coal Development" (Denver: United States Department of Housing and Urban Development, Region VIII for the Northern Great Plains Resources Program).

Wilcox, Leslie D., et al. (1972) Social Indicators and Societal Monitoring: An Annotated Bibliography (New York: Elsevier Scientific Publishing Co.). 
Williams, David C. (1976) "Rapid Growth From Energy Projects: Ideas for State and Local Action: A Program Guide" (Washington, D.C.: Office of Community Planning and Development, U.S. Department of Housing and Urban Development).

Wilson, John 0. (1973) "Quality of Life in the United States: An Excursion into the New Frontier of Socioeconomic Indicators," in Booz, Allen Public Administration Serivices, Inc., "The Quality of Life Concept: A Potential New Tool for Decision-Makers" (National Technical Information Services, PB-225 089).

Wolf, C. P., ed. (1974) Social Impact Assessment (Environmental Design Research Association). 
APPENDIX A

SOCIAL IMPACT ASSESSMENT AND QUALITY OF SOCIAL LIFE INDICATORS 


\section{APPENDIX A \\ SOCIAL IMPACT ASSESSMENT AND QUALITY OF \\ SOCIAL LIFE INDICATORS}

This list is arranged into five sectors: Demography, Economy, Community Structure, Public Services, and Social Well-being. A7l 50 factors 7 isted here are relevant for assessing social impacts, while the 25 factors marked with an asterisk $(*)$ are particularly crucial determinants of the quality of social life in a community. Under each factor are given (a) its recommended empirical indicator, (b) the current (1974) U.S. national average for that indicator, and

(c) the most probable source for obtaining that data.

I. Demography

*1. Population size
a. Indicator: Number of inhabitants in the community
b. U.S. average: Not applicable
c. U.S. Bureau of the Census, Current Population Reports, Series P-25.

2. Amount of population change
a. Indicator: Average annual amount of population change
through natural change and net migration in the community
b. U.S. average: Not applicable
c. U.S. Bureau of the Census, Current Population Reports, Series P-25.

*3. Rate of population change
a. Indicator: Average annual percentage rate of population change in the community
b. U.S. average: $0.8 \%$
c. U.S. Bureau of the Census, Current Population Reports, Series P-25.

*4. Urbanization

a. Indicator: Proportion of the population in the encompassing county (or multi-county area) living in towns of 10,000 or more 
b. U.S. average: $52 \%$

c. State demographic statistics office

5. Sex Ratio
a. Indicator: Number of males per 100 females in the community
b. U.S. average: 95
c. State demographic statistics office

6. Age structure
a. Indicator: Median age of the population of the community
b. U.S. average: 29
c. State demographic statistics office

*7. Ethnicity
a. Indicator: Proportion of the population of the community who are nonwhite
b. U.S. average: 12\%
c. U.S. Bureau of the Census, Census of Population and C.nunty and City lata Book, extrapolated

8. Family status
a. Indicator: Proportion of households in the community with children under 18 present
b. U.'j. average: $44 \%$
c. U.S. Bureau of the Census, Current Population Reports, Series $P-20$

*y. Eulucation
a. Indicator: Median number of years of school completed by persons age 25 or older in the community
b. U.S. average: 12.4 years
c. U.S. Bureau of the Census, Census of Population and County and City Data Book, extrapolated


II. Economy

*10. Gross economic product size

a. Indicator: Annual gross economic product of the community per capita

b. U.S. average: $\$ 6,600$ ( $\$ 5700$ in 1972 dollars)

c. State Department of Commerce or Revenue

11. Gross economic product change

a. Indicator: Annual percentage rate of change in the gross economic product of the community per capita

b. U.S. average: $6 \%(2 \%$ in 1972 dollars)

c. State Department of Commerce or Revenue

12. Economic diversity

a. Indicator: Number of business corporations in the community per 1,000 population

b. U.S. average: 8.7 corporations

c. State Department of Commerce or Revenue

*13. Job availability

a. Indicator: Number of job openings in the community reported to the public employment office per 1,000 persons in the labor force.

h. U.S. average; 101 jobs

c. State Employment Security Office

*14. Employment rate

a. Indicator: Proportion of the labor force in the community current.ly employed

b. U.S. average: $93 \%$

c. State Department of Labor, Manpower Information for Affirmative Action 
15. Female Labor force participation
a. Indicator: Proportion of all women in the community age 18-64 who are gainfully employed
b. U.S. average: $45 \%$
c. State Department of Labor, Manpower Information for Affirmative Action

*16. Personal income
a. Indicator: Median annual personal income in the community per capita
b. U.S. average: $\$ 5,400$
c. U.S. Bureau of the Census, Current Population Reports, Series P-60

*17. Cost of living
a. Indicator: Consumer price index for the community
b. U.S. average: 168 (1967 base)
c. U.S. Bureau of Labor Statistics (avaitable for SMSA's onty)

18. Retail facilities
a. Indicator: Fixed capital assets of all retail facilities in the community per capita
b. U.S. average: $\$ 300$
c. U.S. Bureau of the Census, Census of Retail Trade, Series R672-S-2

19. Property value.
a. Indicator: Total full value of all assessed real estate in the community per capita
b. U.S. average: $\$ 4,200$
c. County or city assessor's office

20. Governmental income
a. Indicator: Total amount of funds received annually
by all local governments from all sources per capita
b. U.S. average: $\$ 550$
c. County and city budget offices 
III. Community Structure

*21. Occupational structure

a. Indicator: Proportion of the total labor force in the community holding professional, executive, managerial, official, or technical jobs

b. U.S. average: $19 \%$

c. U.S. Bureau of Labor Statistics, Employment and Earnings

*22. Neighborhood associations

a. Indicator: Number of active neighborhood associations in the community per 10,000 population

b. U.S. average: Not unknown

c. Knowledgeable local public officials

*23. Service associations

a. Indicator: Number of permanent community-wide service associations per 10,000 population (includes service, fraternal, professional, educational, health ethnic, and political associations, but not churches, political parties, labor unions, business and trade associations, cultural organizations, or recreational groups)

b. U.S. average: 10 associations (estimated)

c. Telephone directory

*24. Residential stability

a. Indicator: Proportion of the total population in the community not moving during the previous five years

b. U.S. average: $57 \%$

c. U.S. Bureau of the Census, Current Population Reports, Series $\mathrm{P}-20$

*25. Housing quality

a. Indicator: Mean market value of all houses in the community, adjusted for price inflation (to 1967 base) 
b. U.S. average: $\$ 13,000$ ( $\$ 22,000$ current)

c. Local association of real estate agents

26. Housing availability
a. Indicator: Proportion of all dwelling units
in the community that are currently unoccupied
b. U.S. average: $6 \%$
c. Local association of real estate agents

27. Voter registration
a. Indicator: Proportion of the population age 18 and older who are currently registered voters in the community
b. U.S. average: $67 \%$
c. County elections office

28. Local government size
a. Indicator: Total number of people employed by local
governments, excluding school systems per 1,000 population
b. U.S. average: 15 people
c. County and c.1ty management offices

29. Cultural organizations
a. Indicator: Total annual budgets of all nonprofit
cultural organizations in the community per capita
b. U.S. average: Not known
c. Local arts commission

30. Social movements
a. Indicator: Number of signifiant social change movements in the community per year, as identified by local newspapers
b. U.S. average: Not known
c. Content analysis of local newspapers 
IV. Public Services

31. Governmental public service capital outlays

a. Indicator: Total annual capital outlays for public services by all local governments per capita

b. U.S. average: $\$ 100$ (estimated)

c. County and city budget offices

*32. Governmental public service operational expenditures
a. Indicator: Tota1 annual operational expenditures for public services by all local governments per capita
b. U.S. average: $\$ 450$ (estimate)
c. County and city budget offices

*33. School capabilities
a. Indicator: Average student-teacher ratio for all grades in the local public school system
b. U.S. average: 22 students
c. Local public school district(s) office

34. Hospital facilities
a. Indicator: Number of hospital beds in the community per 1,000 population
b. U.S. average: 7 beds.
c. Local hospitals

*35. Medical services
a. Indicator: Number of practicing physicians in the community per 1,000 population
b. U.S. average: 1.5 physicians
c. State or county medical association

36. Police protection a. Indicator: Number of police officers in the community
per 10,000 population 

b. U.S. average: 26 police officers
c. County sheriff's office and city police department (s)

37. Fire protection
a. Indicator: Number of fire fighters in the community per 10,000 population
b. U.S. average: 14 fire fighters
c. Local fire departments(s)

38. Public sucial services
a. Indicator: Total annual expenditures by all local governments for public welfare services and benefits per capita
b. U.S. average: $\$ 22$
c. U.S. Social and Rehabilitation Service, Public Assistance Statistics

*39. Private social services
a. Indicator: Total annual budgets of all private social service agencies in the community per capita
b. U.S. average: Not known
c. Local United Way/Fund

*40. Parks and recreational services
a. Indicator: Total capital investment in parks and recreational facilities in the community per capita
b. U.S. average: $\$ 13$
c. County and city budget offices

41. Public transportation
a. Indicator: Total annual expenditures for public transit facilities and services by local governments per capita
b. U.S. average: $\$ 9$
c. County and city budget offices 
42. Public facilities
a. Indicator: Total annual operational expenditures for public facilities (including streets and roads, water, sanitation, and sewerage) by all local governments per capita

b. U.S. average: $\$ 51$

c. County and city budget offices

V. Social Wel1-being (A11 of these indicators are inverse measures of well-being.)

*43. Minority opportunities
a. Indicator: Ratio of nonwhite to white annual family income in the community
b. U.S. average: $62 \%$
c. U.S. Bureau of the Census, Current Population Reports, Series $\mathrm{P}-60$

*44. Women's opportunities
a. Indicator: Ratio of annual earnings of females to males in the community
b. U.S. average: $48 \%$
c. U.S. Bureau of the Census, Current Population Reports, Series P-60

*45. Economic security
a. Indicator: Proportion of families in the community with annual incomes below the established poverty line
b. U.S. average: $11 \%$
c. U.S. Bureau of the Census, Current Population Reports, Series $P-60$

46. Economic equality
A. Indicator: Proportion of all income acquired by the top $20 \%$ of the population in the community
b. $41 \%$
c. U.S. Bureau of the Census, Current Population Reports, Series $P-60$


*47. Personal safety

a. Indicator: Number of violent crimes (murder, manslaughter, robbery, assult, and rape) in the community per 1,000 population

b. U.S. average: 4.6 crimes

c. County sheriff's office and city police department(s)

48. Property safety

a. Indicator: Number of major property crimes (burglary, larceny, and auto theft) in the community per year 1,000 population

b. U.S, average: 44 crimes

c. County sheriff's office and city police department(s)

*49. Personal stability

a. Indicator: Number of arrests for drunkenness, driving while intoxicated, and disorderly conduct in the community per year per 1,000 population

b. U.S. average: 8.3 arrests

c. County sheriff's office and city police department(s)

50. Family stability

a. Indicator: Number of divorces filed for per year in the community per 1,000 population

b. U.S. average: $5.0 \mathrm{filing}$

c. County vital statistics office 
APPENDIX B

FLOW CHARTS 
APPENDIX B

\section{FLOW CHARTS}

The flow charts given here pertain to the five sectors of demography, economics, community structure, public services, and social well-being. Two charts are given for each sector. The first chart in each pair is a model for forecasting future conditions in that sector if the proposed innovation is not implemented ("without the project"), but considers all other change trends that

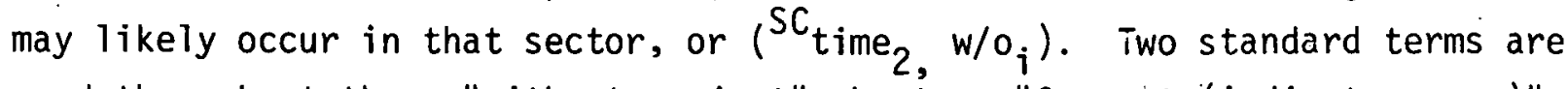
used throughout these "without project" charts: "Current (indicator name)" refers to the presently existing condition of the community on that indicator. The total list of these indicators provides a profile of the community at the present time in that sector. "Expected (indicator name)" refers to the forecasted condition of the community on that indicator at some specified future time, assuming the proposed project is not implemented. The total list of these indicators provides a profile of that sector of the community at that future date without the project, based on both projections of current conditions and trends, and any future changes likely to occur in the community that are not associated with the proposed project (such as new industrial development or the closing of a military base). The difference between the "current" and "expected" figure for each indicator is a measure of the change forecasted in that factor under "normal" conditions.

The second flow chart in each pair gives a model for forecasting future conditions in that sector if the proposed project is adopted ("with the project"),

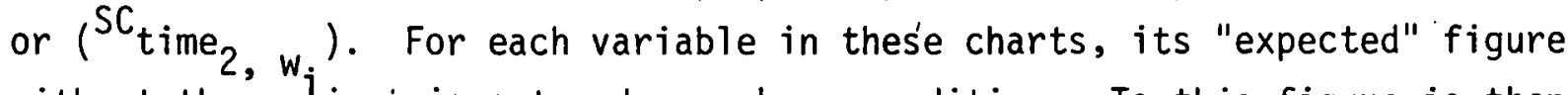
without the project is entered as a base condition. To this figure is then added the "project-stimulated changes" for that factor, as forecasted by the model. These changes would all be directly or indirectly related to the presence of the projected in the community, without taking into account any planned efforts at mitigation (but including existing automatic governmental responses, such as increased state aid to school systems based on enrollment figures). These "project-stimulated" forecasts are not predictions of any 
conditions that might exist by themselves, but are only measures of the effects that the proposed project would likely have on the otherwise existing conditions in the community at a specified future date. The sum of these "expected" and "project-stimulated" figures for any given indicator is the "predicted (indicator name)" figure for that indicator. This is the condition of that factor forecasted to exist at a specified future time if the proposed project is implemented, taking into account both "normally. expected" and "projectstimulated" changes that will likely occur in the community. The total list. of these indicators provides a profile of that sector of the community at the future date that includes the effects of the project. The difference between the "expected" and "predicted" figure for each indicator is a measure of those forecasted effects of the project on that factor.

The charts for each sector contain--down the right-hand side--all of the social indicators relevant to that sector (as listed in Appendix A). Finally, beginning with the flow charts for the economic sector, almost all the predictor variables utilized in any given chart are sociai indicators taken from earlier charts, so that all of these flow charts are interlocked. 


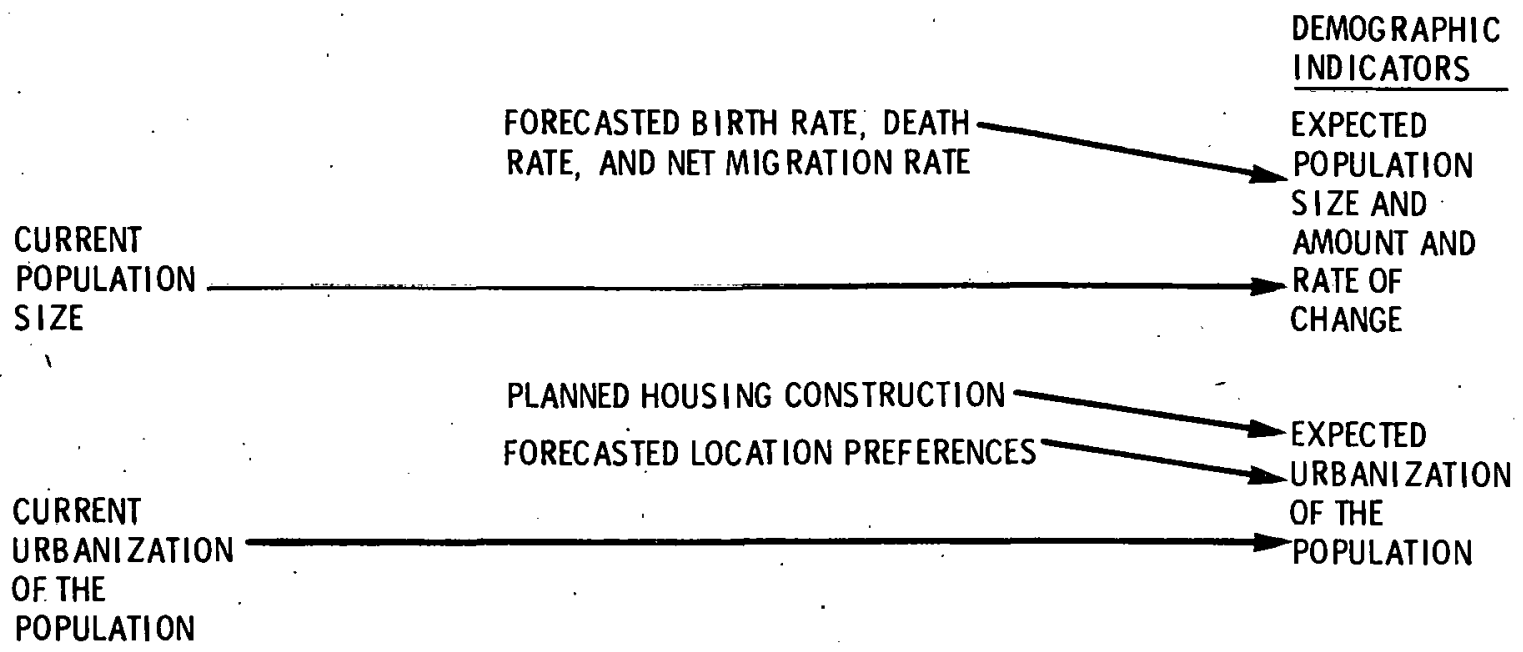

FORECASTED DIFFERENTIAL BIRTH, DEATH, AND NET MIGRATION RATES BY AGE, SEX, ETHNICITY, AND EDUCATION

CURRENT

AGE STRUCTURE, SEX RATIO, ETHNICITY, AND EDUCATION OF THE POPULATION

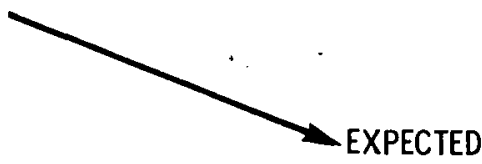
AGE STRUCTURE, SEX RATIO, ETHNICITY, AND EDUCATION OF THE POPULATION

FORECASTED MARRIAGE AND CHILDBEARING PREFERENCES

CURRENT

FNMILY STATUS

OF THE

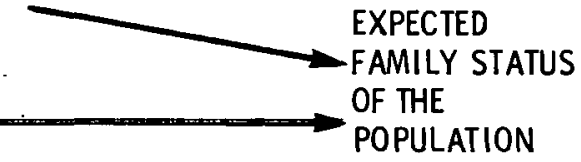

POPULATION

FIGURE B-1. Demographic Flow Chart without the Proposed Project 


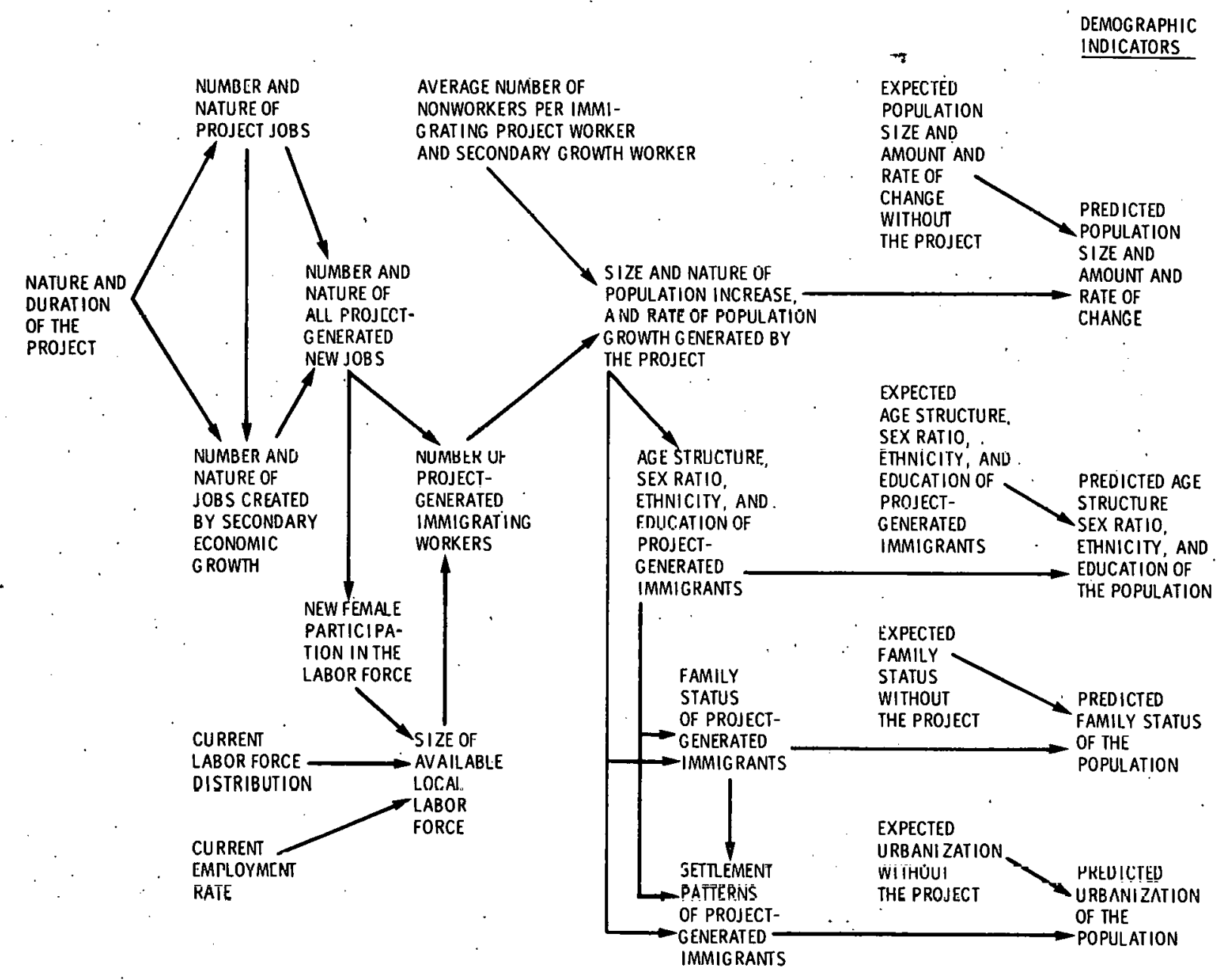

FIGURE B-2. Demographic Flow Chart with the Proposed Project 


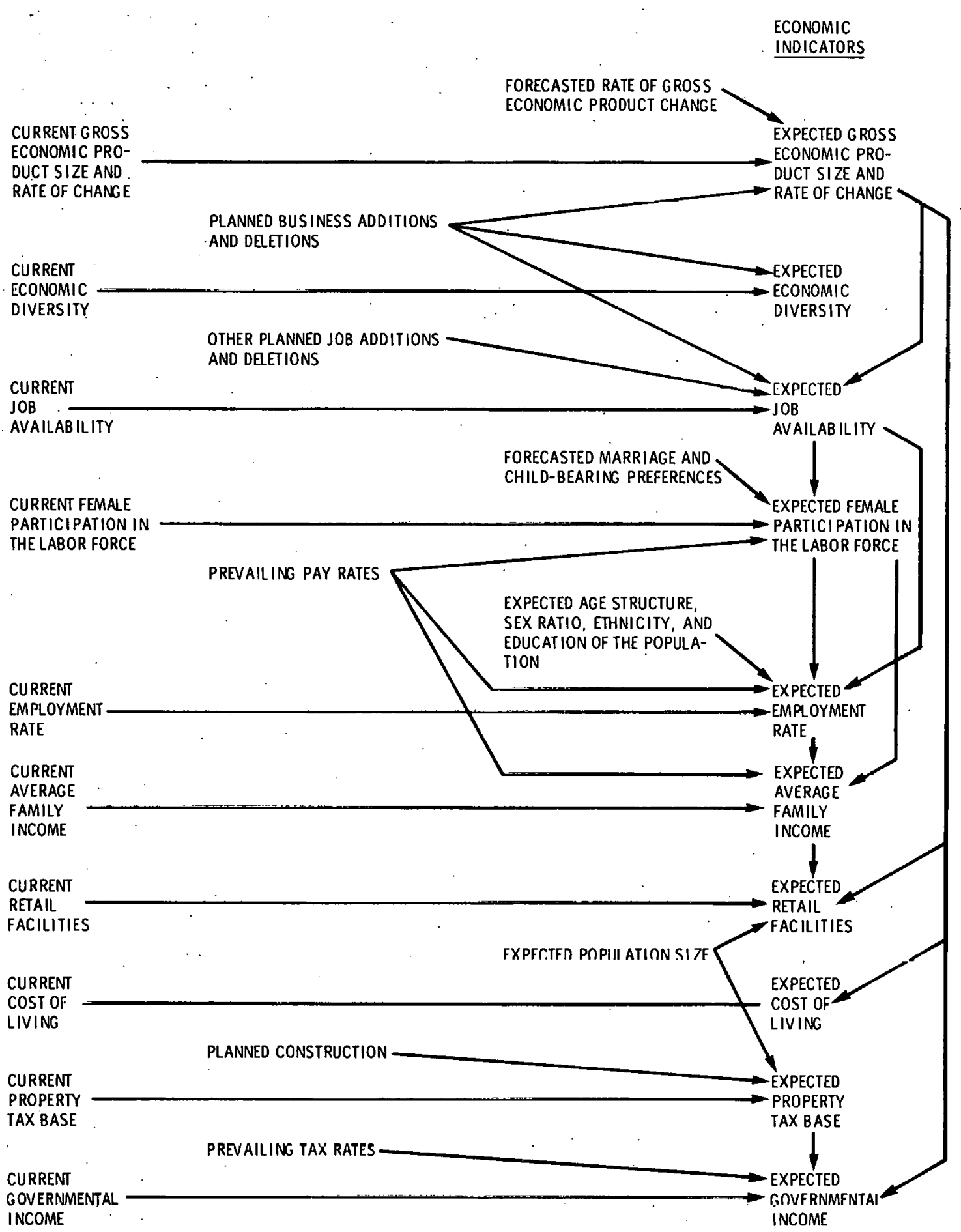

FIGURE B-3. Economic Flow Chart Wi thout the Proposed Project 


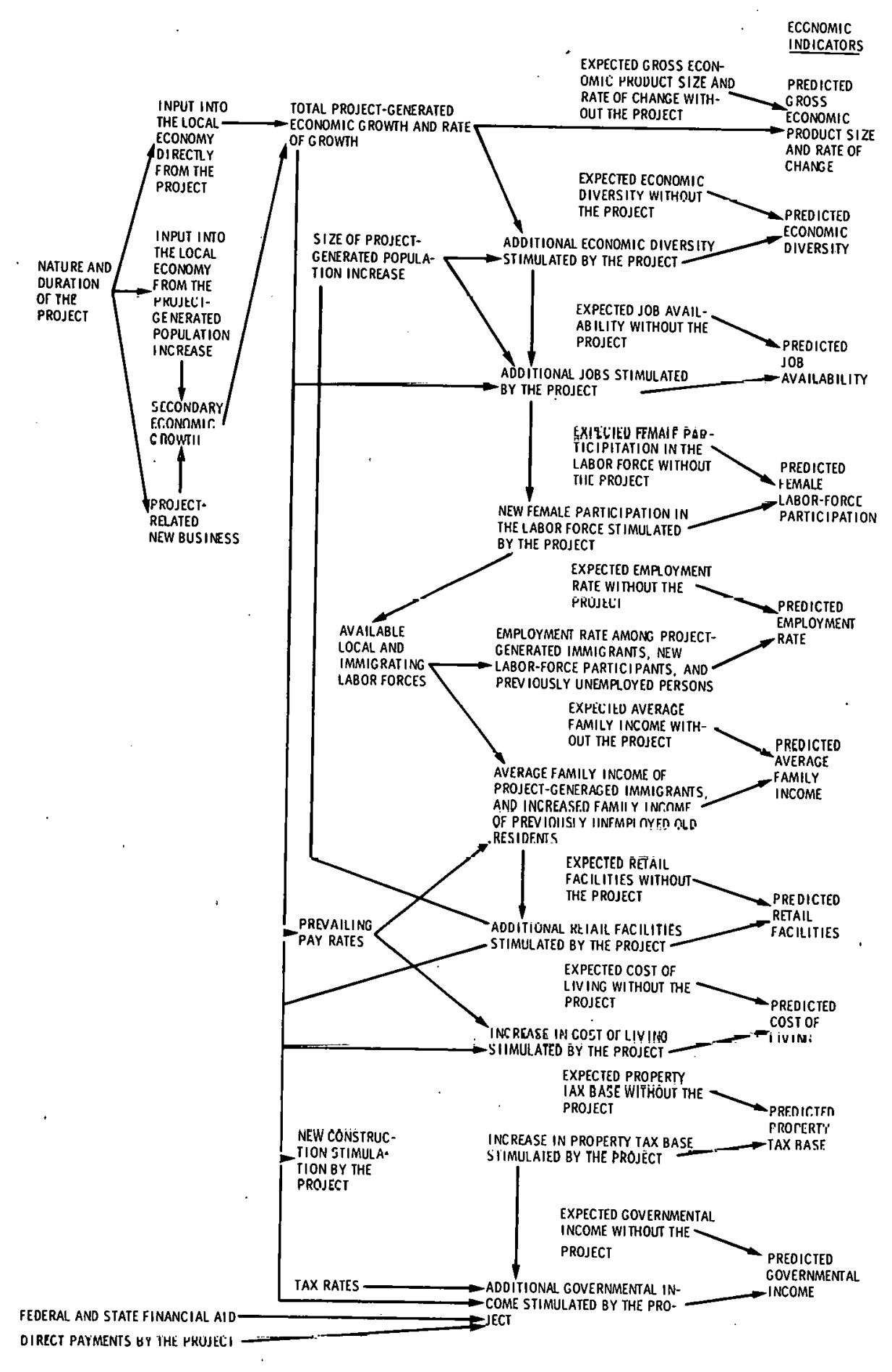

FIGURE B-4. Economic Flow Chart with the Proposed Project 


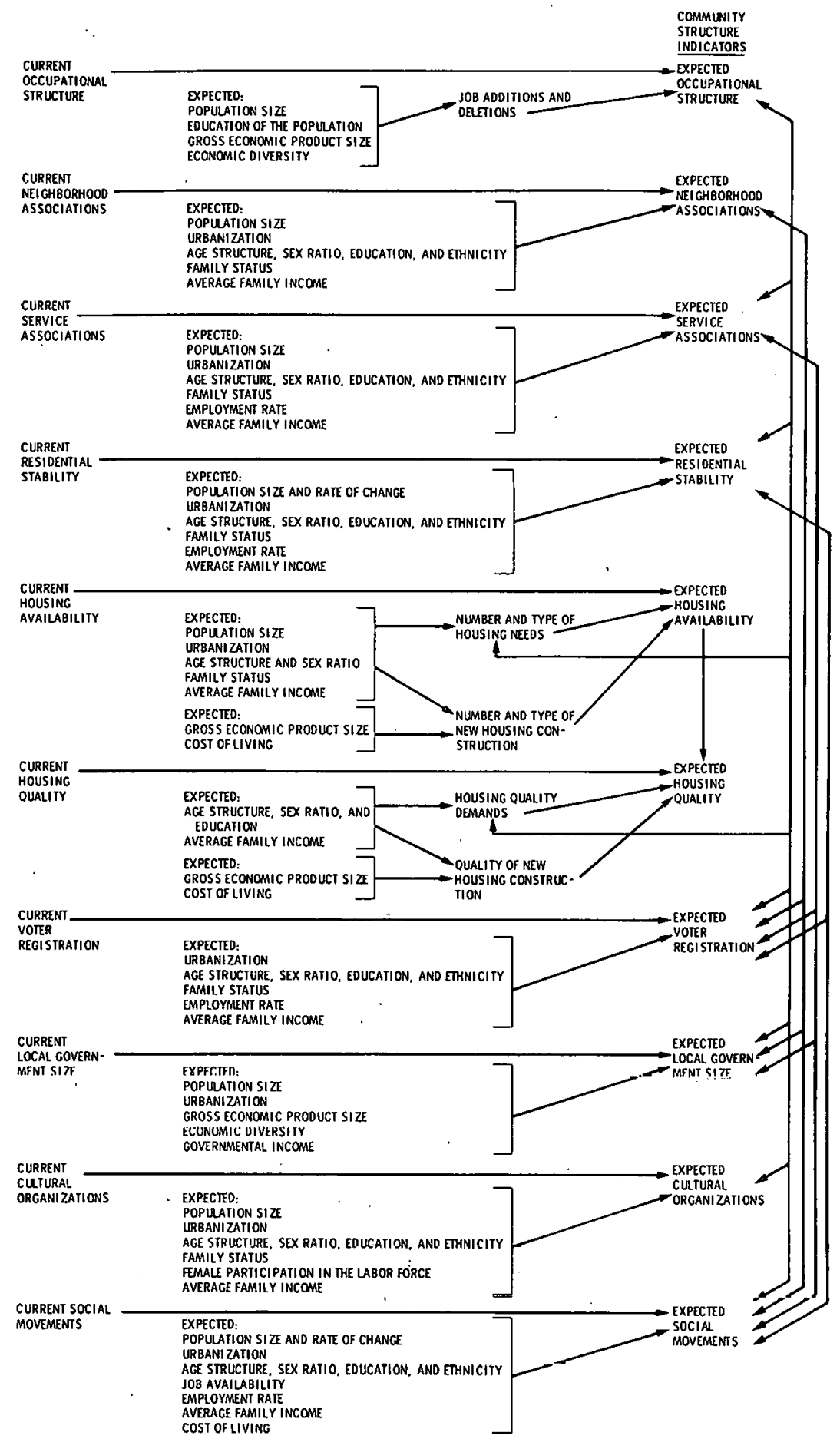

FIGURE B-5. Community Structure Flow Chart without
the Proposed Project 


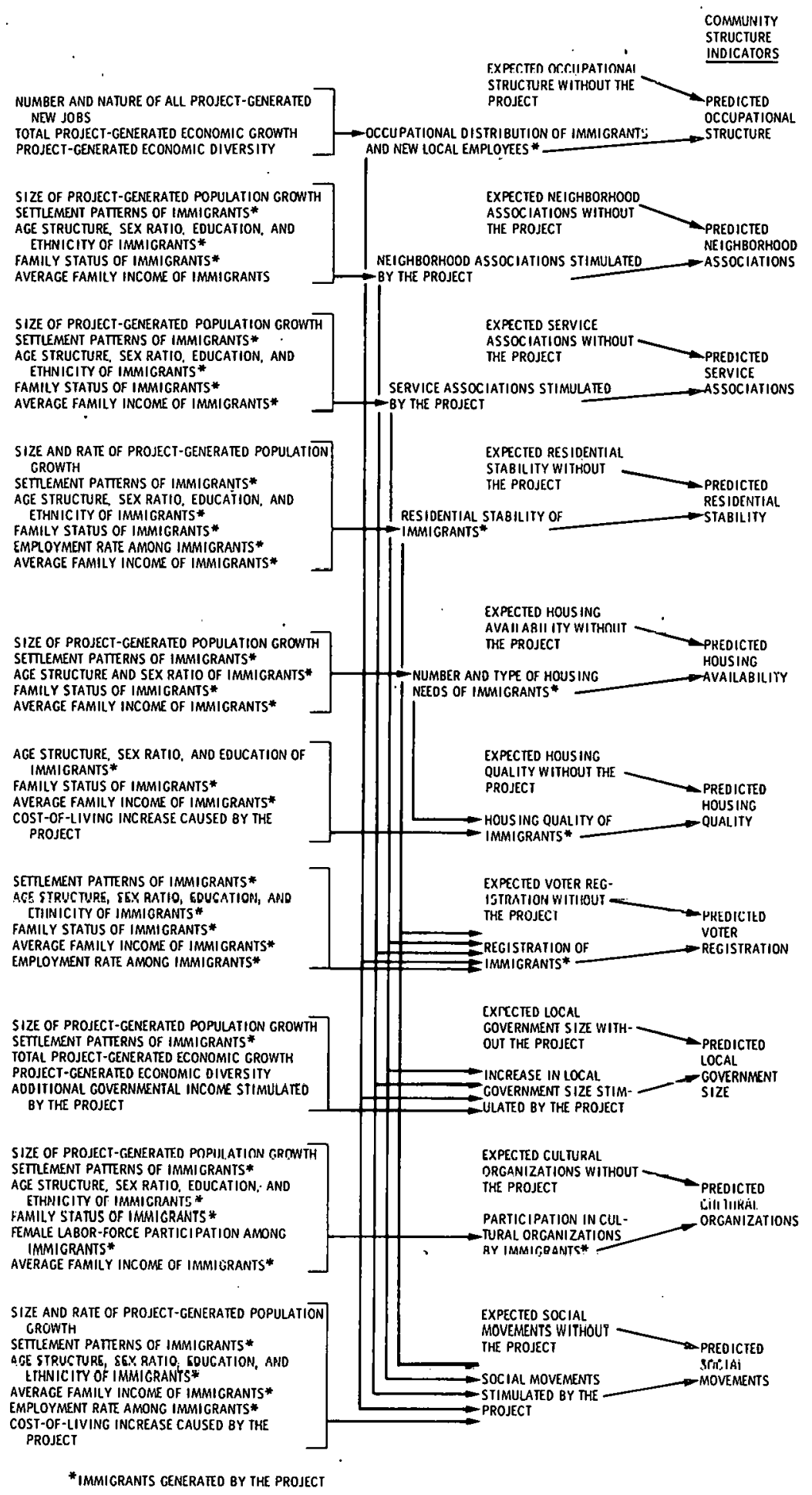

FIGURE B-6. Community Structure Flow Chart with the Proposed Project 


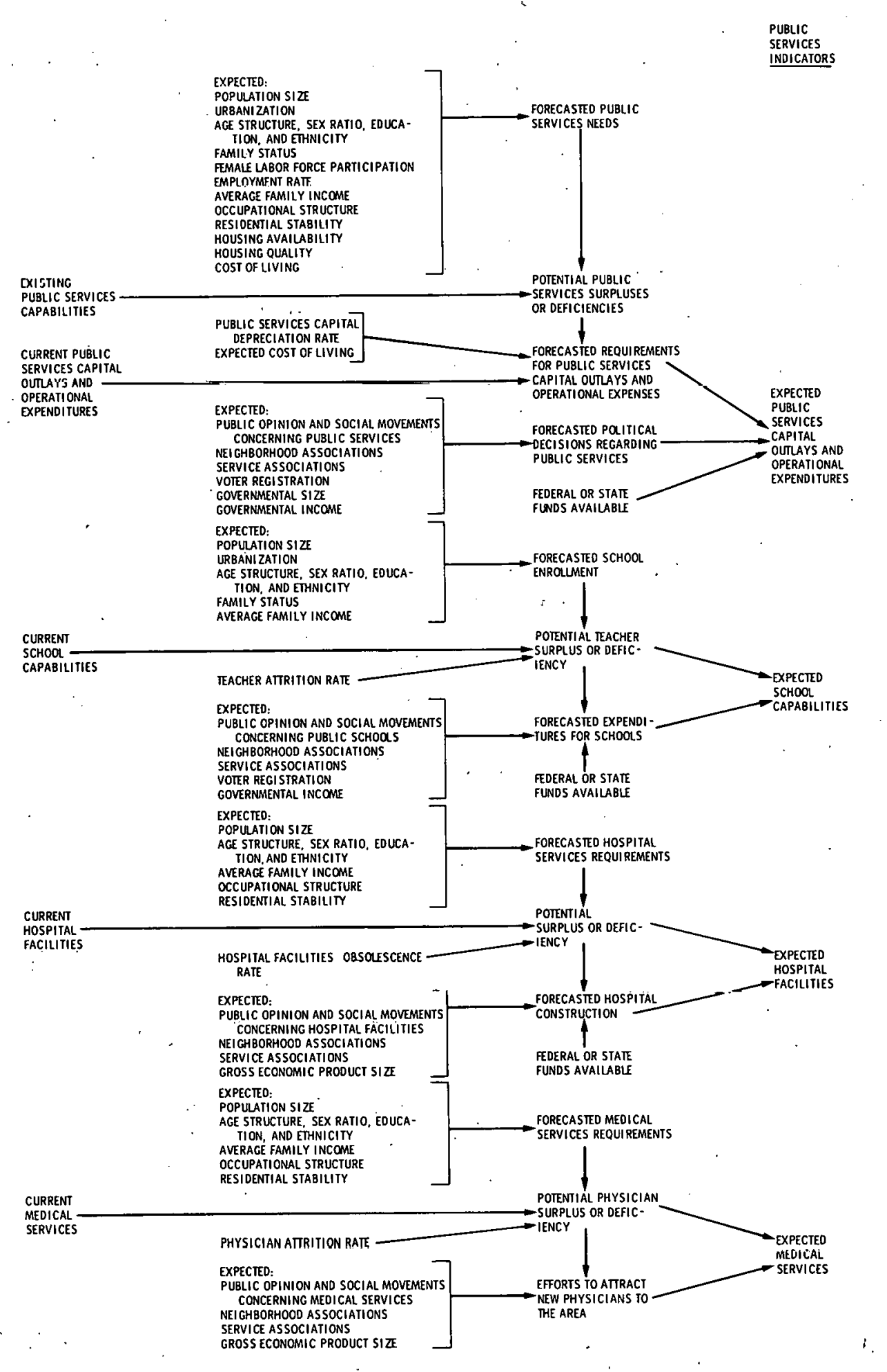

FIGURE B-7. Public Services Flow Chart without the Proposed Project 


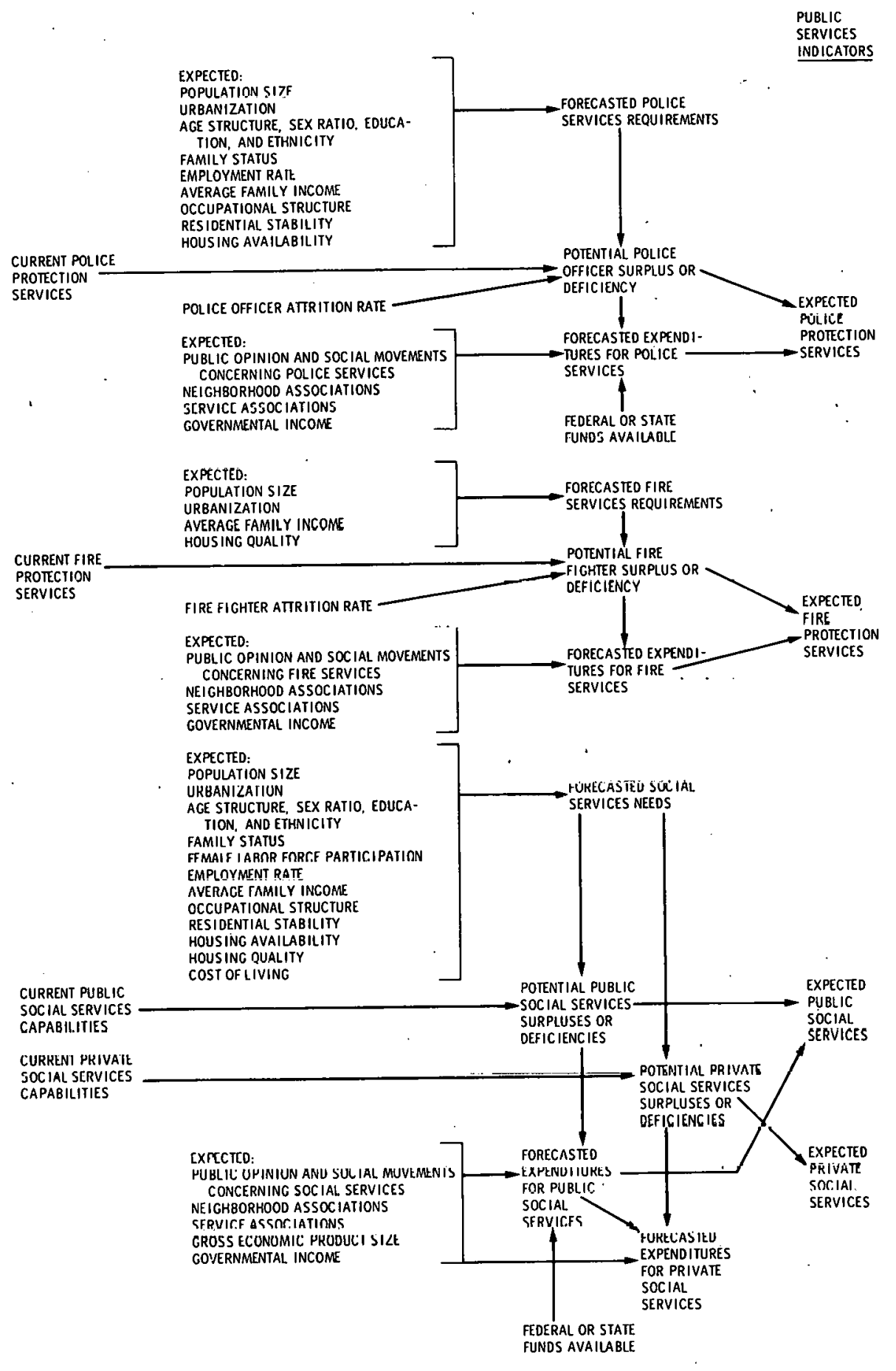

FIGURE B-7. Public Services Flow Chart without the Proposed Project
(Cont'd) 


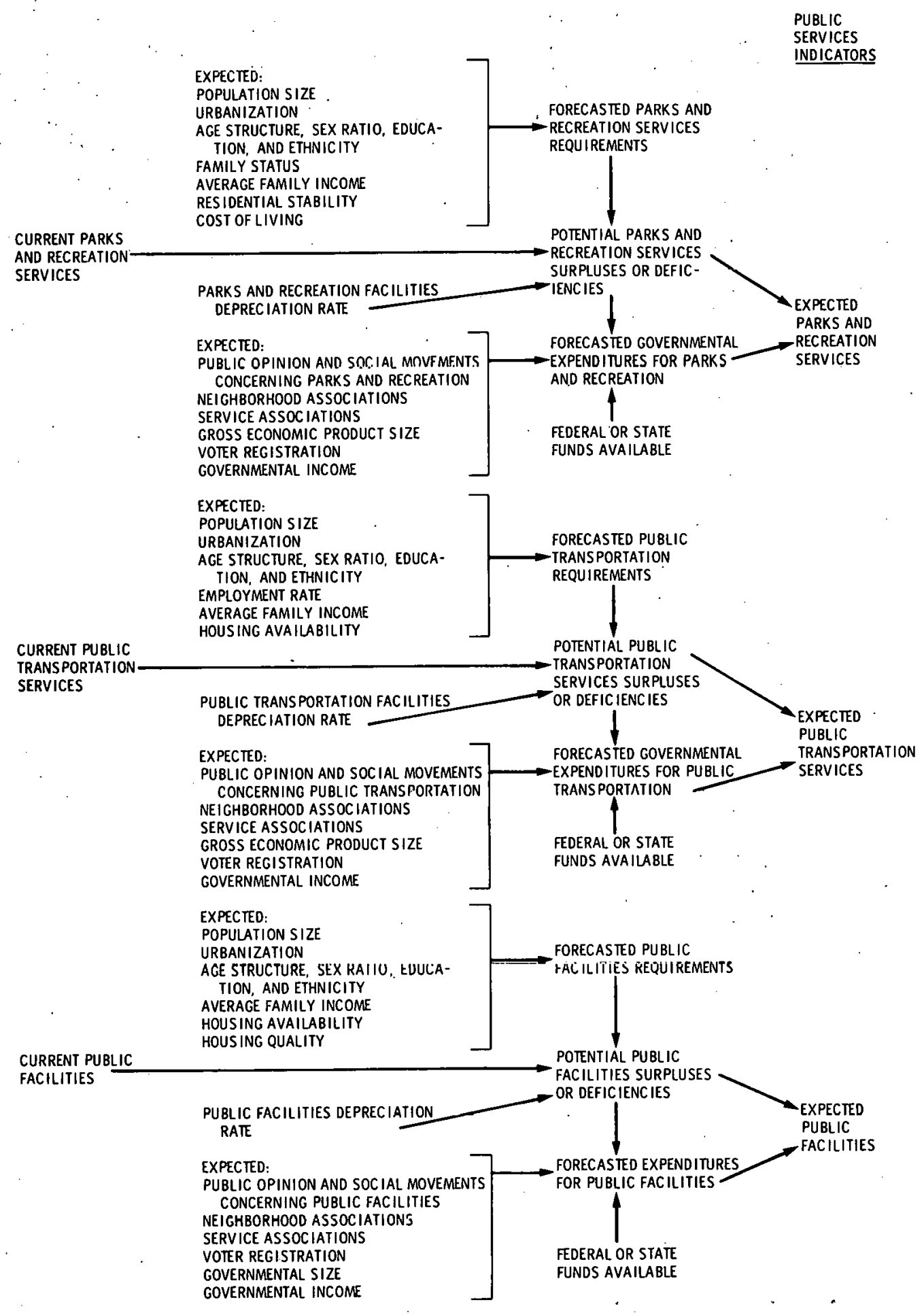

FIGURE B-7. Public Services Flow Chart wi thout the Proposed Project (Cont'd) 


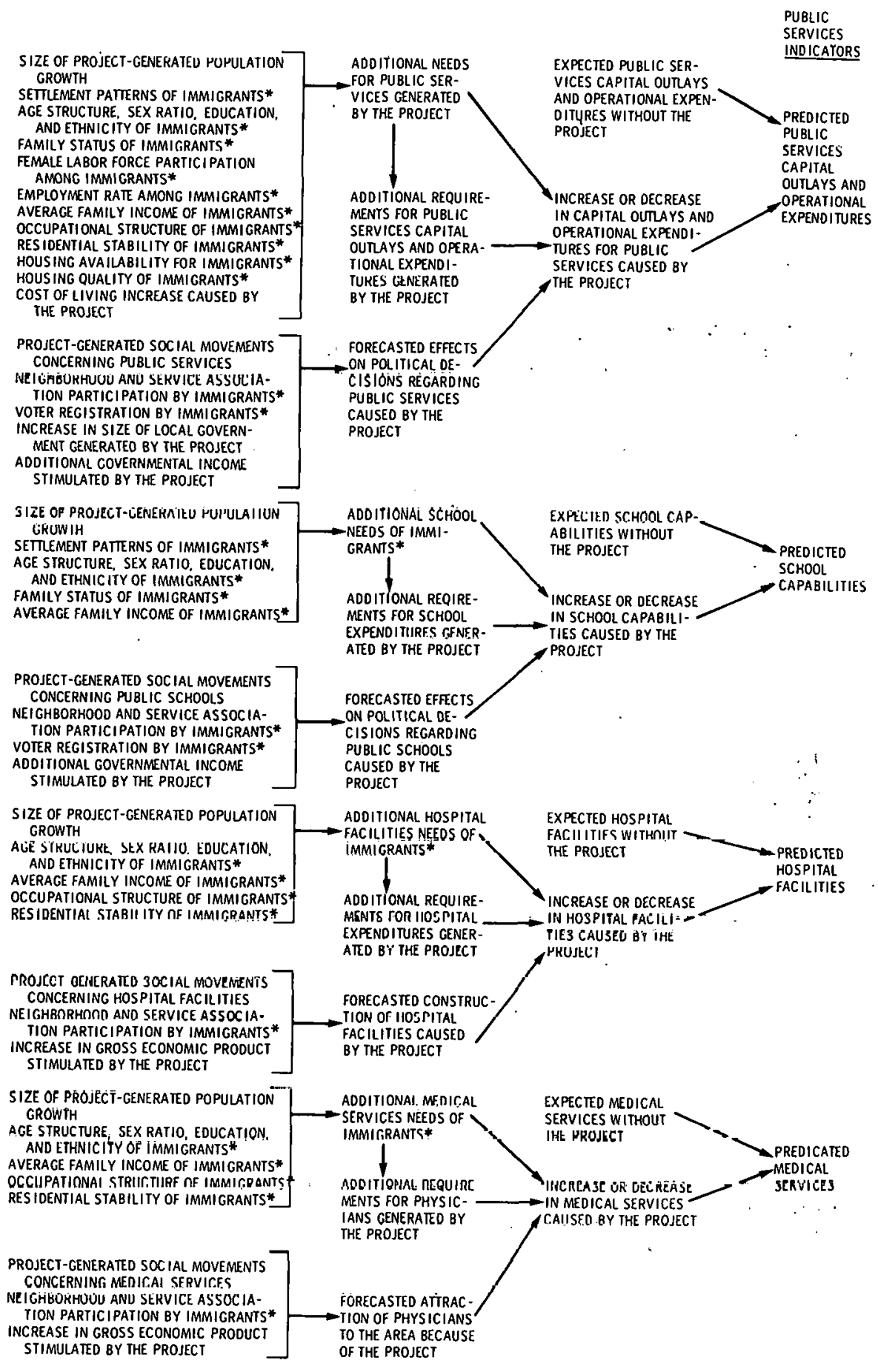

* immigrants generateo by the project

\section{FIGURE B-8. Public Services Flow Chart with the Proposed Project (Cont'd)}




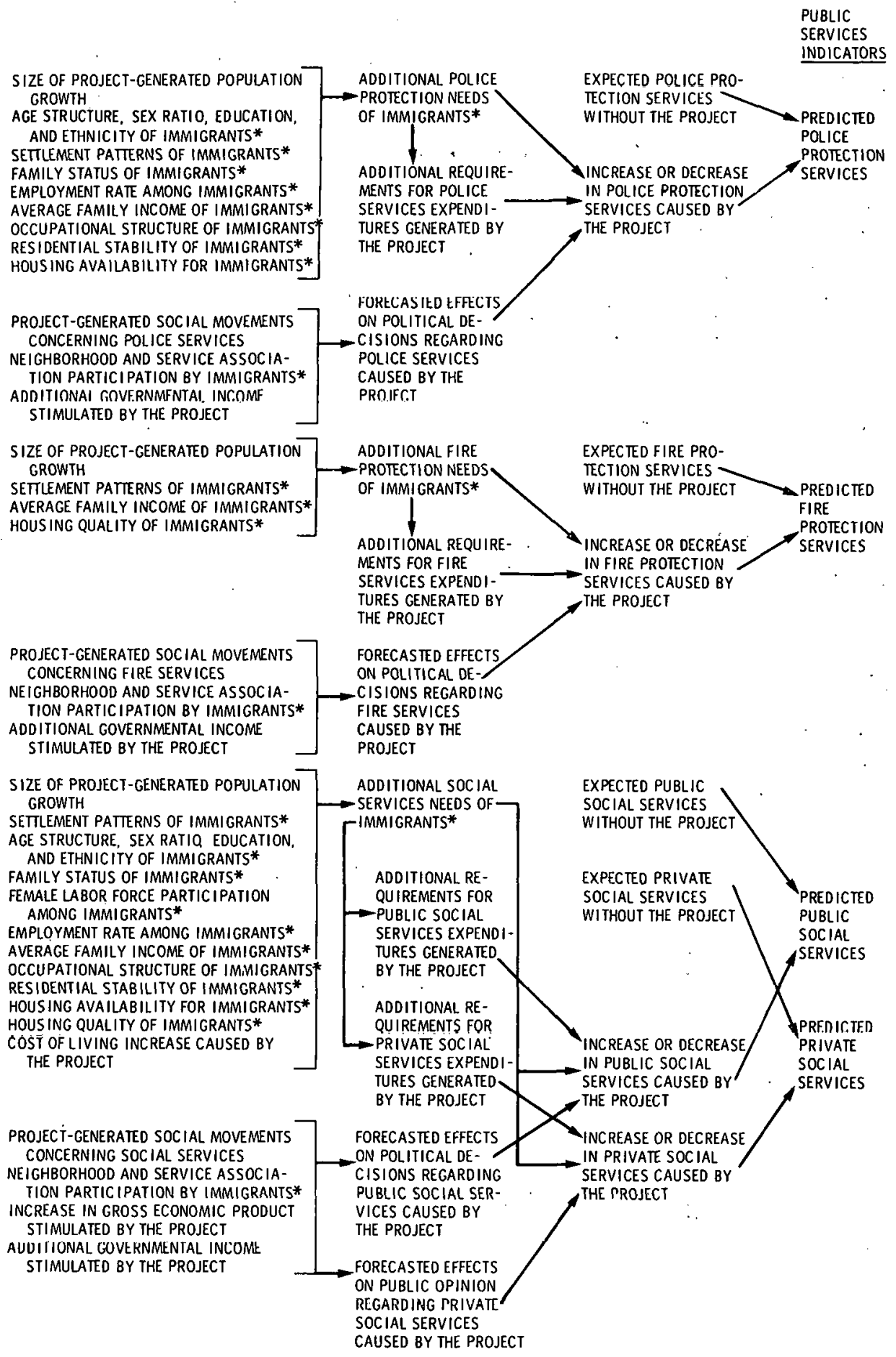

* ImMIgRants Generated by the PRoject

FIGURE B-8. Public Services Flow Chart with the Proposed Project (Cont'd) 


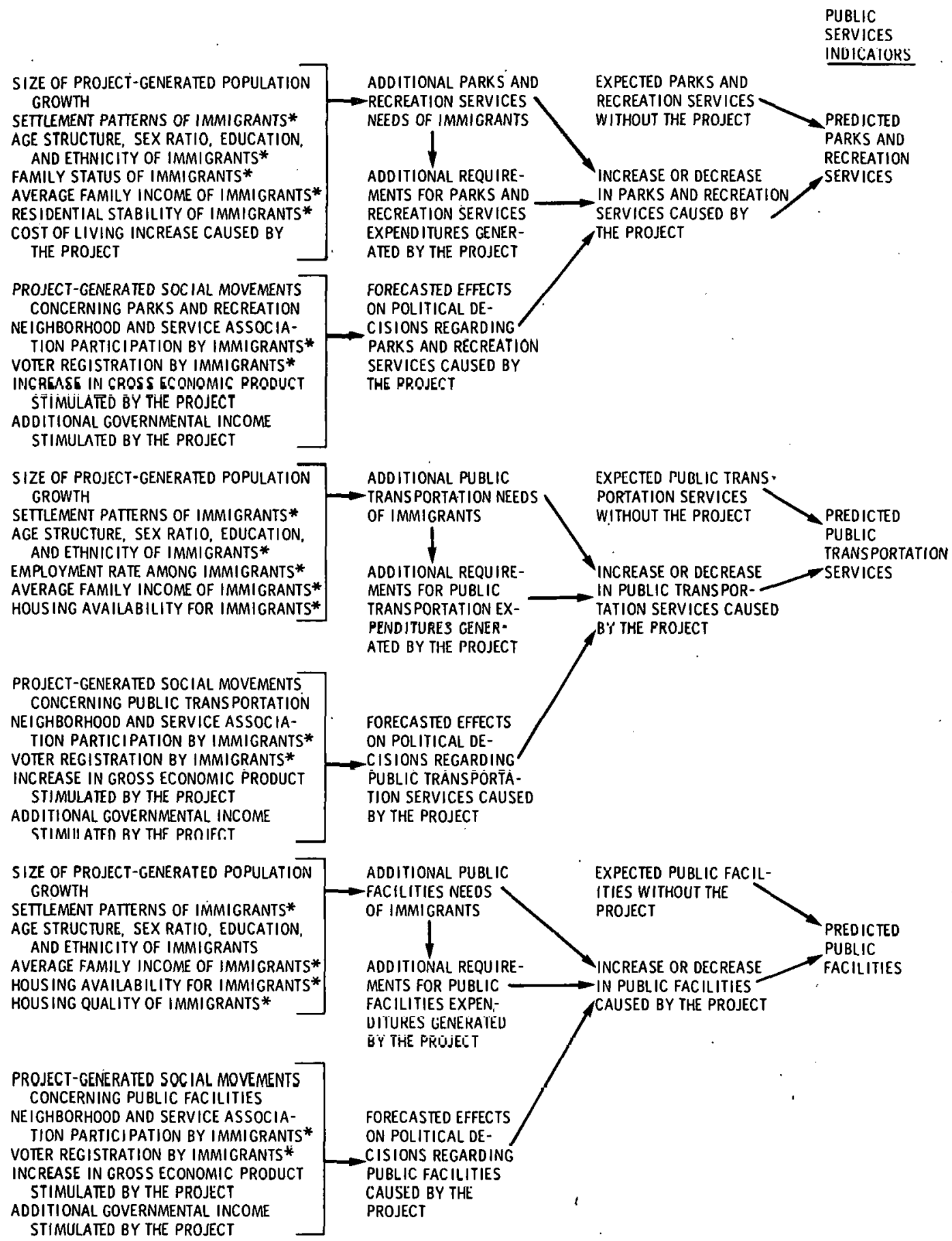

*ImMigrants generated by the PROJect

FIGURE B-8. Public Services Flow Chart with the Proposed Project (Cont'd) 


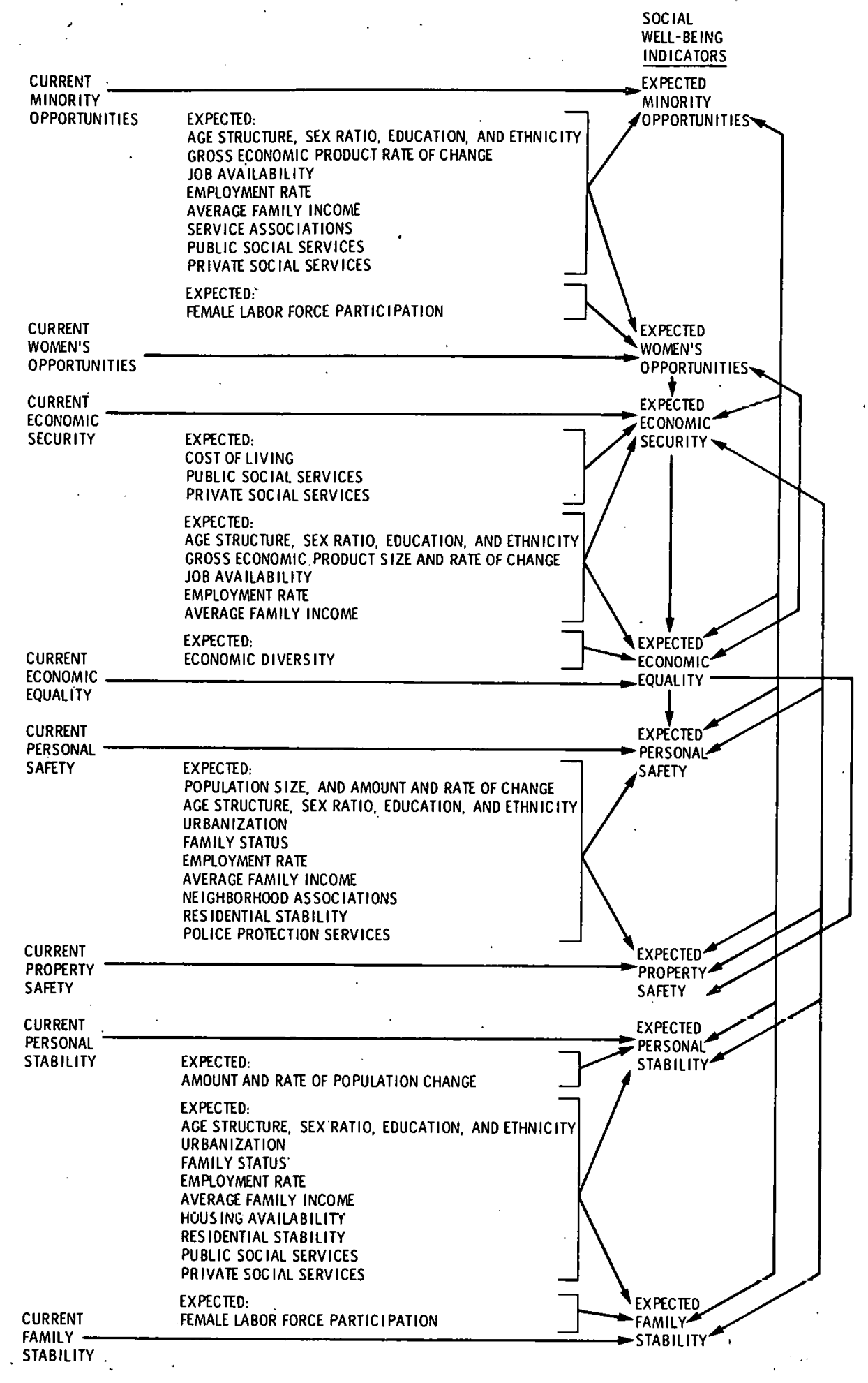

FIGURE B-9. Social Well-Being Flow Chart without the Proposed Project 


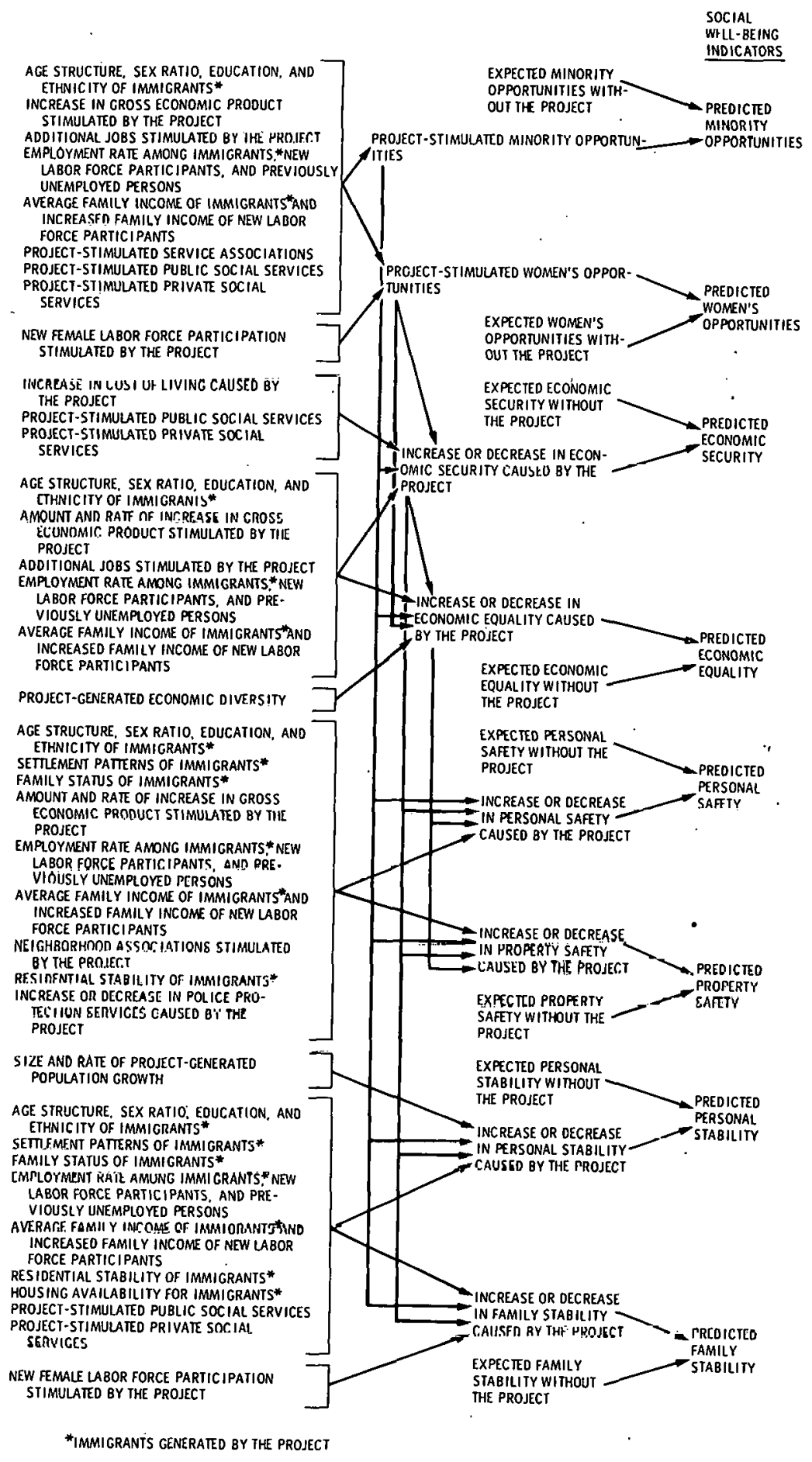

FIGURE B-10. Social Well-Being Flow Chart with the Proposed Project 
No. of

Copies

OFFSITE

D. S. Ballantine

DOE Office of Environmental

Research

Washington, DC 20545

N. F. Barr

DOE Office of Technology

Impacts

Washington, DC 20545

R. P. Blaunstein

DOE Office of Technology Impacts

Washington, DC 20545

W. W. Burr

DOE Office of Environmental

Research

Washington, DC 20545

E. S. Burton

DOE Resource Applications and Evaluation

Washington, DC 20545

R. L. Butenhoff

DOE Office of Environmental Research

Washington, DC 20545

C. E. Carter

DOE Office of Environmental Research

Washington, DC 20545

Paul Cho

DOE Office of Technology Impacts

Washington; DC 20545

A. A. Churm

DOE Chicago Patent Group

9800 South Cass Avenue

Argonne, IL 60439
No. of

Copies

Mrs. Ruth Clusen

DOE Assistant Secretary

for Environment

Washington, DC 20545

J. A. Coleman

DOE Office of Technology Impacts

Washington, DC 20545

C. W. Edington

DOE Office of Environmental Research

Washington, DC 20545

W. 0. Forster

DOE Office of Environmental Research

Washington, DC 20545

P. H. Gerhardt

DOE Office of Technology Impacts

Washington, DC 20545

A. J. Goldberg

DOE Office of. Technology Impacts

Washington, DC 20545

E. E. Held

DOE Office of Environmental Compliance and Overview

Washington, DC 20555

Dr. Joan Hock

DOE Office of Technology: Impacts

Washington, DC, 20545

H. L. Hollister

DOE Office of Environmental Compliance and Overview Washington, DC 20545 
No. of

Copies

P. W. House

DOE Office of Technology Impacts

Washington, DC 20545

A. B. Joseph

DOE Office of Nuclear

Regulatory Research

Washington, DC 20555

J. L. Liverman

DOE Deputy Assistant Secretary for Environment

Washington, DC 20545

F. G. Lowman

DOE Office of Nuclear

Regulatory Research

Washington, DC 20555

D. M. Monti

DOE Office of Technology

Impacts

Washington, DC 20545

W. E. Mott

DOE Office of Environmental

Compliance and Overview

Washington, DC 20545

R. R. Newton

DOE Office of Technology

Impacts

Washington, DC 20545

M. Reilly

DOE Division of Fossil Energy

Washington, DC 20545

G. J. Rotariu

DOE Office of Technology

Impacts

Washington, DC 20545

R. D. Shull

DOE Office of Technology

Impacts

Washington, DC 20545
No. of

Copies

D. H. Slade

DOE Office of Environmental

Research

Washington, DC 20545

J. Swinebroad

DOE Office of Environmental Research

Washington, DC 20545

B. W. Wachholz

DOE Office of lechnology

Impacts

Washington, DC 20545

H. R. Wasson

DOE Office of Technology. Impacts

Washington, DC 20545

W. H. Weyzen

DOE Office of Environmental Research

Washingtion, DC 20545

E. R. Williams

DOE Office of Technology Impacts

Washington, DC 20545

R. W. Wood

DOE Office of Environmental

Research

Washington, DC 20545

27 DOE Technical Information Center

E. Croke

Argonne National Laboratory 9700 South Cass Avenue

Argonne, IL 60439

L. J. Hoover

Argonne National Laboratory 9700 South Cass Avenue Argonne, IL 60439 
No. of

Copies

P. M. Meier

Building 475

Brookhaven National Laboratory

Upton, NY 11973

P. Palmedo

Building 475

Brookhaven National Laboratory

Upton, NY 11973

W. E. Siri

University of California

Lawrence Berkeley Laboratory

Berkeley, CA 94720

D. Layton

University of California

Lawrence Livermore Laboratory

P.0. Box 808

Livermore, CA 94550

E. Hamme1

Los Alamos Scientific Laboratory

P.0. Box 1663

Los Alamos, NM 87545

R. K. Lohrding

Los Alamos Scientific Laboratory

University of California

P.0. Box 1663

Los Alamos, NM 87545

R. M. Davis

Oak Ridge National

Laboratory

P.0. Box X

Oak Ridge, TN 37830

W. Fulkerson

Oak Ridge National

Laboratory

P.0. Box X

Oak Ridge, TN 37830
No. of

Copies

ALASKA

J. Halterman

State Clearinghouse

Division of Policy Development and Planning

Office of the Governor

Pouch AD

Juneau, AK 99801

J. Lowell Jensen

Public Utilities

Commission

Mackay Building

338 Denali Street

Anchorage, AK 99501

G. Martin

Department of Natural

Resources

State Office Building

Pouch $M$

Juneau, AK 99811

C. Quinlan

Department of Commerce and

Economic Development

Mackay Building

338 Denali Street

Anchorage, AK. 99501

Col. G. R. Robertson

District Engineer

Alaska District

Corps of Engineers

P.0. Box 7002

Anchorage, AK 99510

\section{CALIFORNIA}

S. Boris.

Teknekron Corporation

2118 Milvia Street

Berkeley, CA 94704 
T. E. Browne

Electric Power Research Institute

P.0. Box 10412

Palo Alto; CA 94304

R. Crow

Electric Power Research Institute

P.0. Box 10412

Palo Alto, CA 94304

\section{R. Doel1}

U.S. Geological Survey

354 Middlefield Road

Menlo Park, CA 94025

M. Greenburger

Electric Power Research Institute

P.0. Box 10412

Palo Alto, CA 94304

L. Henning

Electric Power Research Institute

P.0. Box 10412

Palo Alto, CA 94304

H. A. Kornberg

Electric Power Research Institute

P.0. Box 10412

Pdlo Altu, CA 94304

D. N. Morris

The Rand Corporation

1700 Main Street

Santa Monica, CA 90406

E. Neblet

DOE Federal Energy

Regulatory Commission

U.S. Custom House

San Francisco, CA 94111

M. Searle

Electric Power Research Institute

P.0. Box 10412

Palo Alto, CA 94304
IDAHO

R. H. Bendio

Idaho Power Company

P.0. Box 70

Boise, ID 83721

D. Guss

Bureau of State Planning and Community Affairs

State House

Boise, ID 83720

L. K. Hall

Idaho Energy Office

State House

Boise, IU 83720

J. McFadden

Energy, Inc.

Box 736

Idaho Falls, ID 83401

M. Neville

Idaho Legislative Council

State House

Boise, ID 83702

K. U. Smith

Public Utilities

Commission

472 W. Washington Street

Boise, ID 83720

R. J. Vissia

Bureau of Reclammation

Federal Buildiriy

550 West Fort Street

Boise, ID 83724

R. N. Wise

Bureau of State Planning and Community Affairs

State House

Boise, ID 83720 
No. of

Copies

\section{ILLINOIS}

J. P. Hartnett

Energy Resources Center

University of Illinois at Chicago Circle

P. 0. Box 4348

Chicago, IL 60680

\section{MONTANA}

J. Binanado

Bureau of Land Management

P. 0. Box 30157

Billings, MT 59107

K. Blackburn

01d West Regional Commission

Fratt Building, Suite 306A

Billings, MT 59101

R. A. Hofacker

Montana Power Company

40 East Broadway

Butte, MT 59701

R. Hulme

State Clearinghouse

Office of Budget and

Program Planning

232 Capitol Building

Helena, MT 59601

M. 0. Murtensen

Energy Advisory Council

c/o Lt. Governor's Office

Capitol Building

Helena, MT 59601

K. Muller

Northern Plains Resource

Council

418 Stapleton Building

Billings, MT 59101

J. Nybo

Energy Advisory Council

c/o Lt. Governor's Office

Capitol Building

Helena, MT 59601
No. of

Copies

W. Opitz

Public Service Commission

122711 th Avenue

Helena, MT 59601

B. Roberts

State Land Use

Planning Bureau

Department of Community Affairs Capitol Post Office

Helena, MT 59601

W. Toml inson

Environmental Library

Room 208A, Natural Sciences

University of Montana

Missoula, MT 59801

A. C. Tsao

Energy Planning Division

Department of Natural Resources

and Conservation

32 South Ewing

Helena, MT 59601

$\mathrm{OHIO}$

Ann Rudolph

Battelle Memorial Institute

505 King Avenue

Columbus, $\mathrm{OH} 43201$

\section{OREGON}

Col. H. L. Arnold, Jr.

District Engineer

Portland District

Corps of Engineers

P.0. Box 2946

Portland, OR 97208

H. Brauner

Conservation and Development Commission

1175 Court Street, N.E.

Salem, OR 97301 
No. of

Copies

Charles Davis

Public Utility Commissioner

Labor and Industries Building

Salem; OR 97310

R. A. Duncan

Northwest Power Pool

920 S. W. Sixth Avenue

Room. 1210

Portland, OR 97204

L. Harris

Western Aluminum Producers

As sociation

P.0. Box 8484

Portland, OR 97207

Dr. M. Hellickson

Oregon State University

Agricultural Engineering

Department

Corvallis, OR 97331

J. Hoozen

Bonneville Power Administration

P.0. Box 3621

Portland, OR 97208

J. Jaksch

Corvallis Environmental

Research Laboratory

U.S. Environmental Protection Agency

Corvalis, OR 97331

M. Katz

Bonneville Power Administration

P.0. Box 3621

Portiand, OR 97208

J. E. Kiley

Bonneville Power Admịnistration

P.0. Box 3621

Portland, OR 97208

D. J. Lewis

Pacific Northwest Utilities

Conference Committee

920 S.W. Sixth Avenue

Portland, OR 97204
No. of

Copies

J. C. Loos $1 i$

Bonnevile Power Administration

P.0. Box 3621

Portland, OR 97208

F. D. Miller

Oregon Department of Energy

528 Cottage, N.E.

Salem, OR 97310

R. T. Miller

Northwest Natural Gas Company

123 N.W. Flanders Street

Portland, OR 97209

0. Osborne

Oregon State University

Electrical Engineering Department

Corvallis, OR 97331

Maj. Gen. W. E. Peel

Division Engineer

North Pacific Division

Corps of Engineers

210 Custom House

Portland, OR 97209

G. A. Perrault

Portland General Electric Company

621 S.W. Alder Street

Portland, OR 97205

R. E. Pelerson

Pacific Power and Light

Public Service Building

Portland, OR 97204

C. L. Sauvie

Portland General Electric

Company

621 S.W. Alder Street

Portland, OR 97205

J. T. Stiles

Pacific Power and Light

Public Service Building

Portland, OR 97204 
No. of

Copies

C. H. Watkins

Bonneville. Power Administration

P.0. Box 3621

Portland, OR 97208

J. L. Williams

Portland General Electric Company

621 S.W. Alder Street

Portland, OR 97205

J. W. Wolfe

Oregon State University

Agricultural Engineering Department

Corvallis, OR 97331

W. K. Woods

Energy Facility Siting Division

Department of Energy

528 Cottage, N.E.

Salem, OR 97310

W. Young

Intergovernmental Relations

Division

Office of the Governor

240 Cottage Street, S.E.

Salem, OR 97310

$\underline{\text { UTAH }}$

J. A. Barnett

Western States Water Council

220 South Second East,

Suite 200

Salt Lake City, UT 84111

\section{WASHINGTON}

\footnotetext{
F. S: Adair

Washington State Department of Commerce and Economic Development

01ympia, WA 98504
}

No. of

Copies

Co.1. C. J...Alkaire

District Engineer

Walla Walla District

Corps of. Engineers

Building 602, City-County

Airport

Walla Walla, WA 99362

L. Bradley

Washington State Energy Office

1000 Cherry

Olympia, WA 98504

J. Brar

Washington State University

Pullman, WA. 99163

W. E. Bruner

Pacific Northwest Regional

Commission

1205 Washington

Vancouver, WA 98660

F. Claggett

Office of Community Development

State of Washington

400 Capitol Center Building

Vancouver, WA 98660

L. E. Coate

U.S. Environmental Protection

Agency

1200 Sixth Avenue

seattle, WA 90101

G. Culp

Culp, Dwyer, Guterson, and Grader

Hoge Building

Second and Cherry

Seattle, WA 98104

H. G. Curtis

Public Power Council

P.0. Box 1307

Vancouver, WA 98660 
No. of

Copies

J. W. E1lis

Puget Sound Power and

Light Company

Puget Power Building

Bellevue, WA 98009

H. C. Elmore

Pacific Northwest Utilities Conference Committee

P.0. Box 1231

Wenatchee, WA 98801

L. E. Hall

Puget Sound Power and

l,ight. Company

Puget Power Building

Bellevue, WA 98009

H. W. Harding

Washington Water Power Company

P.0. Box 3727

Spokane, WA 99220

G. Hinman

Washington State University

Pullman, WA 99163

H. Kosmata

Washington Public Power

Supply System

3000 George Washington Way

Richland, WA 99352

J. W. LaFond

City of Seattle

Department of Lighting

1015 Third Avenue

Seattle, WA 98104

D. J. Lane

Pacific Northwest River Basins Commission

1 Columbia River

P. 0. Box 980

Vancouver, WA 98660
No. of

Copies

N. Lewis

Office of Program Planning and Fiscal Management

State Planning Division House Office Building

01ympia, WA 98504

B. Pearson

RIS Library

Department of Ecology

01 ympia, WA 98504

R. Polzin

Energy Facility Site

Evaluation ronuncil

820 East Fifth Avenue

Olympia, WA 98504

Col. J. A. Poteat, Jr.

District Engineer

Seattle District

Corps of Engineers

1519 Alaskan Way South

Seattle, WA 98134

D. Renberger/G. F. Bailey

Washington Public Power

Supply System

3000 George Washington Way

Richland, WA 99352

J. B. Robertson

DOE, Room 1992

Federal Building

915 Second Avenue

Seattle, WA $981 \% 4$

P. H. Rose

Mathematical Sciences

Northwest, Inc.

P. 0. Box 1887

Bellevue, WA 98009

E. T. Shaw

Utilities and Transportation Commission

Highways-Licenses Building

01ympia, WA 98504 
No. of

Copies

R. G. Sheehan

City of Seattle

Department of Lighting

1015 Third Avenue

Seattle, WA 98104

R. Tillson

Washington Public Power

Supply System

3000 George Washington Way

Richland, WA 99352

B. C. Thomas

Puget Sound Power and Light Company

Puget Power Building

Bellevue, WA 98009

M. Walsh

Department of Ecology

State of Washington

0lympia, WA 98504

W. C. Wolkenhauer

Washington Public Power

Supply System

3000 George Washington Way

Richland, WA 99352

R. Woodruff

Washington Public Power

Supply System

3000 George Washington Way

Richland, WA 99352

\section{WYOMING}

A. J. Eliopulos

Public Service Commission

Supreme Court Building

Cheyenne, WY 82002

D. B. Freudenthal

State Planning Coordinator's Office

Office of the Governor

State Capitol

Cheyenne, WY 82002
No. of

Copies

D. Hoffman

Mineral Development Division

Department of Economic Planning and Development

720 West 18th Street

Cheyenne, WY 82002

\section{ONSITE}

2 DOE Richland Operations

Office

P. W. Gottschalk

H. E. Ransom

.77 Pacific Northwest Laboratory

W. J. Bair

C. H. Bloomster

D. L. Brenchley

J. B. Brown

S. M. Brown

N. E. Carter

D. B. Cearlock

M. Clement

J. W. Currie

A. E. Davis

D. E. Deonigi

D. W. Dragnich

D. R. Drewes

W. J. Eadie

D. L. Elliott

L. E. Erickson

D. W. Fraley

T. J. Foley

J. C. Fox

C. A. Geffen

P. L. Hendrickson

10 D. L. Hessel

W. T. Hinds

R. L. Hooper

J. J. Jacobsen

J. C. King

J. W. Litchfield

S. Marks

P. J. Mellinger

A. R. 01sen 


\section{ONSITE}

E. L. Owzarski

D. S. Renné

W. H. Rickard

W. F. Sandusky

L. C. Schmid

W. H. Swift

W. L. Templeton

B. E. Vaughan

M. L. Warner

R. D. Widrig

G. L. Wilfert

Economics Library (20)

Publishing Coordination (2)

Technical Information

Files (5)

27 Human Affairs Research Center (HARC)

C. Cluett

M. Green

J. A. Hebert

S. M. Nealey

M. Mertaugh

M. E. $01 \operatorname{sen}(.20)$

C. Sawyer

R. E. Schuller 